\title{
Human Rights versus Corporate Rights: Life Value, the Civil Commons and Social Justice
}

\author{
JOHN MCMURTRY \\ Department of Philosophy, University of Guelph
}

\begin{abstract}
This analysis maps the deepening global crisis and the principles of its resolution by life-value analysis and method. Received theories of economics and justice and modern rights doctrines are shown to have no ground in life value and to be incapable of recognizing universal life goods and the rising threats to them. In response to this system failure at theoretical and operational levels, the unifying nature and measure of life value are defined to provide the long-missing basis for understanding the common interest, human rights and social justice - that is, the universal life necessities of humanity across cultures and the evolving civil commons infrastructures to ensure them. In contrast, the treaty-imposed corporate rights system miscalled "globalization" is structured to predate life means and support systems at all levels with no accountability beyond itself. Only the logic of life value, human rights and life-protective law, it is concluded, can comprehend or govern this inherently life-blind and cumulatively eco-genocidal regime.
\end{abstract}

\section{Breaking out of the Box of Life-Blind Rights}

The deepest problem we have with rights in general is that we have no life-value criterion whereby to tell whether a right is good or bad. Thus the dominant rights of our epoch-property rights in money capital-remain presupposed even if they cumulatively threaten terrestrial and human life organization by their globally lifeblind demands. Indeed these rights now rule our economic, political and cultural worlds with no accountability to the life requirements of human beings, ecosystems or, unprecedentedly, even sovereign states. Reigning since the English, American and French revolutions centuries ago, they have become incrementally absolute and total in the last 30 years. Yet any deeper value principle to determine whether these increasingly totalitarian rights are valid has remained unconceived. Marxian analysis is itself stuck within the capitalist system's contradictions with rights themselves conceived as merely system functions, and no state party, political theory or movement defines the life-value standards to reset the system to coherence with human and planetary life requirements.

Private property in money capital with no limit thus continues as an a-priori assumption of market and state activities across borders. As we know, under this 
system less than $1 \%$ of the population of the world have increasingly more wealth than the bottom $90 \%$, and the social suffering which follows this disparity gets worse. Yet since John Locke and the private-property revolutions he provides the canonical justifications for in England and America, any idea of relating privateproperty right to human needs is undiscussed in public discourses while economic theory itself rules out the connection a-priori. At the same time the criterion of what a human need is across cultures and selves does not exist in received theory or policy discussion. Private money rights to more without end are assumed with no life value to ground their legitimacy, their limits, or their performative requirements.

We have to go back to John Locke to find any discussion of these issues, and even so, what he says is fork-tongued. He specifies three provisos of an individual property right claim in his historic Second Treatise of Government which was published within a year of the English revolution against James II in 1688. His justification of the conditions for the legitimacy of private property are lifegrounded, but for the last time in his work and subsequent market doctrine: (1) "mixing one's labour with" the property to entitle it; (2) "always good enough left over for others"; and (3) "no waste or spoilage" of it (Locke, 1980, p. 21). Yet while Locke's rhetoric of freedom and democratic accountability is recited almost word for word in the U.S. Declaration of Independence, his life-grounding conditions of private property have been ignored since their magniloquent statement at the beginning of the Treatise, including by Locke himself. Having made the case at length for this "natural right" by these three justifications, he erases them with a stroke of the pen with the words "the introduction of money" (Locke, 1980, p. 23). ${ }^{1}$ A subordinate clause within a 10-line sentence is enough for this disappearance act. Locke's shell-game has stood since - a synecdoche of the era. Once his lifegrounded provisos have vanished without a trace, fateful implications follow.

To resolve this and related deep-structural problems, the life-value test is defined and explained by which we tell whether any claimed right, however powerful it is in the world, is sound or not, and to what extent. Private property right itself-from personal fixed possessions to corporate kingdoms - is neither holus-bolus justified nor rejected, but grounded in and tested by its life value. The general theory behind my analysis is life-value onto-axiology, what I have spelled out in depth for UNESCO (McMurtry, 2010). The onto of the concept refers to ontology, literally "the philosophy of being"; and the axiology refers to theories of what is of value, truth being a primary value. Yet because multiplied disciplinary divisions into fields and areas of specialty exclude any unifying principle of value, a major incapacity of thought has evolved. Even connected life and life-support systems' collapse across the world cannot be detected in its causal mechanism or life-value resolution.

\section{Right to Life and Pro-Life Reduced to False Slogans}

One major cognitive block against understanding has been the slogan "right-to-life" attached to America's most popular issue of life-value contention-a woman's right to end her pregnancy. When I first introduced life-value theory in generic form to the Canadian Philosophical Association's Annual Meeting in 1998, a well-known feminist philosopher, Alison Jaggar, repudiated the idea as more "right-to-life" 
advocacy. I report this position to illustrate the metaphysical stupefaction that has come with the internalization of this slogan in a distinguished feminist philosopher's mind. Life value has been so pervasively equated with an embryo in a woman's body that re-grounding in a coherent conception cannot compute. While such an ontoethical reductionism is seen to be fatuous once examined, it conforms to a ruling syntax of thought that is life-blind at a global level, which is the greatest problem of our age. Expressed in the so-called "right-to-life" slogan, it excludes almost all of life from its referent. With even philosophers internalizing such conception, the need to re-ground in life-coherent meaning and method becomes self-evident, a turning point of humanity's evolution (McMurtry, 2009, pp. 69-91; McMurtry, 2010a). As it stands, the abortion issue poses "woman's right to choose" as in ultimate conflict with "the right to life of the unborn human being." Legions of people adopt one side or the other in sustained elaboration of the one or the other position, ignoring the common life-ground that life-value understanding begins with-that is, that life is good, and is better the more coherently inclusive its life-fields and ranges in thought, felt being, and action. This forms the primary axiom of life value. ${ }^{2}$ In contrast, the opposing sides of this issue (and countless others) privilege a standpoint of exclusive right in either-or disjunction. Here as elsewhere, life-value understanding goes underneath this one-sided structuring to the deeper ground of life value itself, and applies the life-value test to both sides. Thus the normalized circle of sterile conflict found in rights conflicts in general - in which each side obscures the underlying principle of life value in attachment to an aspect which excludes the other-is reset to comprehend the wider common ground of life value itself to resolve dispute in terms of this more ultimate and unifying meaning. Life-value analysis therefore always goes to what is at stake in life capacity gain or loss-a life re-grounding which is foreign to the global corporate-rights reign. Life-value method identifies the extent to which any side stands - or does not stand-for life value, and exposes false pretences masking the underlying life-value issues. Here as elsewhere, there is one ultimate criterion of life-value/disvalue across domains, the formal axiom of life value and its converse. As testing will show, it applies across value conflicts.

With respect to the woman's "right to choose" whether to continue bearing an embryo or fetus, it follows, life-value analysis recognizes that the principal life value here lies with the person who organically bears the life. Gain or loss of life value and decision on how to go living better or worse is hers by the objective life coordinates of life itself. For she alone in the world is the direct experiencer and carrier of it. All concept and image thought is borne by her. The felt side of being within is carried by her. She and not anyone else lives the action of the one organism. All of these facts are undeniable - that is, they cannot be life-coherently denied-and all are basic to the "right to life" of the pregnant woman herself and the fields of life she organically bears. This is not another argument for private property, as the woman's right has been reduced to. It is a life-value diagnosis which explains and limits rights. In distinction, the embryo she bears has as yet little or none of these life-bearing values. It only comes to bear them in growing through the ontogeny of embryonic existence to fetal differentiation, to eventually the stage when full human being has developed: that is, when it is no longer life-coherently conceived as merely "part of the woman's body," but a self-organizing unity capable of independent fields of life learning, sentience, affect and body action. 
Thus in accordance with this development by life-value measure, the embryo/fetus within the woman's organism is of intrinsic worth insofar as it realizes and bears these life fields and value-beginning with intra-uterine movement, felt side of being, and image thought in early form. Yet conversely in proportion to nonexistence of these fields of life value, the embryo or fetus is correspondingly lower in life value - not only, as Aldous Huxley clinically observes in Point Counter Point, "a potential fish," but also a human potential (Huxley, 1947, p.2). Observe that lifevalue analysis does not import the imagined future of a human person into present value any more than it does the image of a full-grown fish, but still recognizes projective imagination and its embryonic referent have life-value in their own right by life-value measure. In short, life-value analysis brings us back to ground. It affirms the right of both bearing mother and embryo/fetus as life value within themselves to the extent of fields of life borne - not by mere projection, which in this age has also conferred rights of super persons on lifeless corporate stocks, a connected derangement of the ruling syntax of value and meaning.

Together more than either, woman and offspring have compounded life value in the same being, the pregnant woman. Here they incorporate in their unity opposing life values only by conceptually constructed reification of a non-person as a person-a metaphysical inversion that has oppressed the world at different levels. The passionate certitude with which these reifications are proclaimed is familiar in cults, but now has mainstream megaphones proclaiming them. What is morally deranged is that the rights of non-persons and their interests override the life interests of real persons in the name of life. The life-value onto-ethic recognizes the disorder, and grounds in human life as coherently conceived. More generally, it stands for what consistently enables human and ecological life together (the life coherence principle) and upholds it to the most inclusive level possible without life-value loss (the life compossibility principle). Guided by these principles, almost any case of life-sacrificial trade-off is understood as preventable beforehand-although one would hardly know this in the endless positing in our culture of the "necessity" of pesticides, prisons, lay-offs, environmental destruction, foreign wars, and so on. Behind these social habits of life sacrifice lies a deeper and fatal problem. The rules and rights by which we live are ungrounded in life and life value and the slowmotion collapse of planetary life infrastructures signals this across domains.

\section{Finding Our Lost Life-Value Ground and Measure: The Common Life Interest and Ground of Legitimate Rights and Social Justice}

Instituted exclusion of the common life ground and interest follows logically from the atomic division of interests into competing rights in automaton selfmaximization - the life-blind value syntax of the age. The principle of life value goes beneath this agon of rights to the underlying common life-ground which is the base of all terrestrial value. It explains the validity of any and all positions by the lifevalue comprehension it stands for, seeking beyond competing partialities to coherence with life requirements without whose satisfaction life capacities are always despoiled. It understands this as the common life interest which takes into account objective life requirements at ecological, social and individual levels. It 
therefore recognizes that human rights and rules must cohere with the common life support systems that enable the reproduction of all, or else disaster follows. Humanity's common life interest is thus understood to begin with the universal life support systems that all human life, life conditions and fellow life depend on, the ultimate bottom line of terrestrial existence. This life-ground is, accordingly, the real and unseen base of all legitimate human rights-what they must cohere with to be valid. This ultimate foundation of rights is, however, not recognized by economic, ethical, political and rights discourses. Life-value understanding thus requires this comprehension, and rejects any position which does not as invalid and unsound. It works by this life-coherence principle towards a resetting of meaning to deep rights, what enables individual human life consistently with the reproduction of terrestrial life support systems through generational time. All legitimate rights cohere in virtue of this common life-ground that enables the compossible validity of each.

It therefore follows from life-value onto-ethics that one can only justify a right as ultimately legitimate if it enables life in a way not possible without it - the necessity condition of the right joined to its required coherence with other life systems. For example, the human right to living space not violated by forces external to it is the life-value foundation of private-property rights. This was their historical justification before they were debased as absolute rights which take account of neither condition of legitimate rights. Any right has limits, and life space is one-most obviously overridden in such claims as the claimed rights of the Nazi regime to lebensraum, or global corporations to other societies' life resources. A legitimate right is thus defined by both the life necessity and life coherence of its good. The primary axiom and its converse explains the general life-value base here in universal principle, with margins of life-range gain or loss the life-value measure of the necessity of any right and the compass of their coherence with each other. The human vocation, in turn, is to be of living worth in these terms, with right and obligation arising where reduction of human life capacities results without their fulfilment. Consider, for example, the human right to clean water and the corresponding obligation to provide for it at both social and individual levels. What is required at the baseline of understanding and prescription is an incontestable and sufficient criterion of life necessity coherent with others' same necessities. Such a criterion must meet three problems which are typically regarded as insuperable, but are perfectly soluble: (i) to distinguish needs from mere wants and habits; (ii) to provide a criterion which is consistent with and works for all needs; so that (iii) it clearly applies across diverse ways of life and individual differences. The baseline criterion of life necessity, in other words, yields the ultimate principle of validity of both human rights and obligations, and thereby the essential structure of social justice. What is due to and from human beings, the ancient formula of justice, right and obligation, is understood throughout in systematic and objective life-value terms.

Life-value analysis has grounded in a universal criterion of life necessity or need and its corresponding good since its inception: to wit, $N$ is a need if and only if, and to the extent that, deprivation of N's good always results in reduction of life capacity. This may be called the $N$-criterion, that which denotes, and only denotes, any and all life needs whatever. Thought experiment as well as the findings of science will demonstrate that there is no vital need that does not satisfy this criterion, and that no claimed need that does not is a life need. Both also confirm that there is no life capacity that is not also measurable by this principle-for example, the need for 
drinking water measured by the calibrated life capacity loss without it through time. Both poles of life capacity admit of many levels and kinds of capability test. Note, however, that the life-value meaning of capability is not that of Amartya Sen and the capabilities literature (Cohen, 2008; Nussbaum, 2000; Nussbaum \& Sen, 1993; O’Neill, 1998; Sen, 1992). It refers strictly to life capabilities - or more exactlytheir ranges of function for life not to be demonstrably reduced in its capacities. No such principled ground or qualifications are defined in the received meaning of "capabilities." This is why political and corporate rhetorics have been quick to pick up on the concept-merely "ability to perform functionings"-which validates private preferences for non-life functionings, like private motor powers. These may meet no life need at all, but violate them in both the owner (who needs the exercise instead) and, more so, other life (which is oppressed by its effects of noise, pollution and life-field occupation). Martha Nussbaum, the other best known leader of the capabilities literature, goes further than Sen in "taking a stand" on what capabilities are, but her schema lacks any defined principled ground or any criterion whereby the claimed life goods can be anchored, tested, and integrated. The missing life-ground and criterion is the $\mathrm{N}$-criterion.

Nothing that does not satisfy this objective and comprehensive criterion qualifies as a necessary good or capability. Nor can it have a just right to it as distinguished from a mere privilege. Again contrast this to Sen's position that all capabilities we might "have reason to value" count as valid. Such a criterion legitimates the right to any commodity which people "have a reason to value." Thus a personal sports vehicle with 6-foot tires or a 500 horse-power marine engine one desires to have to be "safe and well-served" qualifies. What criterion in the capabilities literatures rules against these capabilities as good? As in the capitalist market of choice, there is none. Corporations accordingly talk about their "capabilities" all the time, and those of their products - giant gas-fuelled personal motors, fast-repeat guns, exciting video kill games, two-pound burgers piled high, and so on. All grant the abilities to "perform functionings" that "the individual chooses," and everyone is given a "reason to value" them. Until a life-value criterion is built in, the worst can and does happen in the name of "choice," "capability," and "value."

Sen is concerned with equality of capabilities and rights to them, however, whereas the market system selects for inequality with no concerns. All that matters for its value system is that people pay. While the market is bound by money-demand, Sen understandably wants those without it to have more equal standing. So far, so good. But again the question persists at a general level. What if the desired capability for which people claim a right is for what stunts or violates life capacities at an ecological or organic level? The issue is simply avoided, and this avoidance conforms to an underlying syntax of value which regulates beneath recognition at both market and high-theory levels. In light of its life-blind inner logic, a question is posed by life-value principle. How can corporate rights-to exploit the resources of the world to maximally satisfy what individual consumers have a right to choose have any limit to despoliation of life fields and support systems outside their exchanges? Neither market theory nor received rights doctrines can meet the problem. With no life-value requirement entering as a condition of the legitimacy of these rights and freedoms, two fatal outcomes are predictable in principle: a collapsing planetary life system and social injustice beyond human bearing. 
Many will protest that cultural and individual differences and freedoms make any universal principles of good and bad impossible, or undesirable, or both. For example, some choose to satisfy their need for food in the form of fish and beans, others by meat and potatoes, and still others by vegetables and fruits, with many further variations among these menus. Hence the false inference arises that even the need for food is not universalizable because of these cultural and individual differences. More careful consideration resolves the problem, however, because it recognizes that the organic need is for a complement of nutritional food which can be spelled out across these different fares by the objective $\mathrm{N}$-criterion and primary axiom of value. No one "decides for others" this or any other life necessity and good. It is a necessity of life recognized by a scientifically verifiable criterion of life-value understanding, and it admits of endless degrees and choices within its objective principle of determination. Whether recognized or not, the objective criterion of life value always remains a constant, and so too the life-value ground of rights and social justice. The test is in all situations always whether life capacities are more restricted or reduced in range without the life necessity and good than with it. Empirical science can confirm or disconfirm, but all need everywhere is always this. Right to what is not needed by these objective and comprehensive life criteria, conversely, cannot therefore be a deep or legitimate right, or a requirement of social justice. This is a primary conclusion of life-value onto-axiology, and is open to counter-argument any step of the way.

Yet how manifold is the resistance to understanding the self-evident at this principled level. Still another avoidance is to argue that the need-criterion of legitimacy of right is reductionist for people's lives beyond need. Yet again one asks: what exactly is worthwhile that is not an expression or enjoyment of a life capacity? If nothing is, and need is solely that without which life capacities are reduced, what of true life value can be ruled out? Thought experiment confirms that nothing of value can be ruled out. As we consider the universal life needs which satisfy the Ncriterion - a long research study whose conclusions are reported for examination ahead - we find that there is nothing worthwhile in life that is excluded because all that people do or choose to do requires life capacities, and they in turn require the goods that meet needs to flourish, however free and unique they may be. Whatever the manifold variations and choices within the generic goods of these universal life needs, no life-coherent possibility is pre-empted. Moreover, all that a human life can have a legitimate right to is that which is needed to enable life capacities to live and flourish as human - the universal life needs and goods which derive from the primary axiom and the $\mathrm{N}$-criterion. Explanation needs to be very exact and conclusive here because there has been a longstanding and world-wide confusion on these issues. Amidst tireless variations on the slogans of "individual and consumer differences and choice" and "what is a need to some is a want to others," the absence of any ground of understanding of humanity's ultimate directive meaning defines the age. Postmodern, relativist and sceptical theories of all kinds explicitly or tacitly refuse to accept any universal good or necessity at all. In the background, for over 2500 years philosophers have largely avoided the issue of universal life needs and any common life-ground of moral meaning. Economists in particular have systematically conflated needs and desires with no recognition of their ultimate distinction by life necessity itself. 
Life needs or necessities, that without which life capacities are lost, form the common life-ground and interest of humanity which has been abandoned. Conditioned market desires, preferences and wants are the opposite in principle because without them no life capacity is reduced, while all admit of the excesses and perversions that need rules out. Life-value research has therefore recognized that identifying the human life necessities and goods actually required by human flourishing is an unfulfilled task, and meets it with one common test-whether anyone could live without it and not suffer a loss of life capacity. One cannot do without oxygenated air or potable liquid or caloric intake in any degree, for example, without a proportionate reduction or destruction of life capacity. Thus develops the life-value calculus. It identifies in every of life good the scientifically establishable limits of life capacity range and the degrees of its reduction correlating with the degrees of deprivation of it. For example, one cannot live six minutes without any breathable air, a day or so without water, a week without any food, and so on. The italicized parameters apply across need-capacity domains, with very different lines of necessity and loss from deprivation of different universal life necessities. Insufficient breathable air leads quickly to incapacitation by the degree of deprivation, but deprivation of open space or light take far longer to show the loss of ability to function through range. Nonetheless they are universal life necessities and goods, in the correspondingly qualified sense. And so on through the entire framework of universal life needs/goods spelled out ahead. Consider a paradigm need in illustration. The nourishment requirement is many-sided in calorie, protein, and vitamin necessities of intake, with research establishing required range quantities for size and age parameters and corresponding physical degeneration by significant deprivations. Deprivation of communicative culture, on the other hand, is more complex and less dramatic in its effects, but is still expressed in life capacity loss. Although no reading or writing tools for a writer would score far higher as a disabling deprivation than it would for someone preferring music and play as human communication forms, people without any of these are made subhuman. Although need satisfiers and choices vary immensely, reduction of life capacities without any of them is clear, and variously quantifiable by loss of life-function range.

To move into still further spheres of these universal human life necessities and goods - the real basis of legitimate human rights - we may consider what is often blinkered out as a merely subjective or cultural issue. Consider a human life without anyone caring for its existence at any level. Life-value analysis can recognize such a deprived life is a kind of hell, although capacity loss from its deprivation is not as instantaneous as is life without potable water. There is still a human life necessity of supportive care or "love" which some say the greatest need of all. Certainly without it people variously lose life capacity including the will to live itself, and infants and children variously shrivel up and die to the world without it, as research has shown across the primates. In every case there are implications for human rights and obligation corresponding to the life-value loss and provision involved. Still another universal life good and necessity across cultures admitting of very different forms is the need for a physical or natural environment in some integrity of form. This is why people having to live in an environment of squalid disorder is a human right violation and social injustice. Deterioration of the life fields of thought, felt being and action follows - as has been shown by animal welfare research with even 
livestock reduced in their vital signs of alertness, brightness of eye and skin sheen if they are deprived of environmental form and stimulus.

At this point explanation calls for some unifying complete set of these universal human life goods/needs/ necessities without which human beings variously suffer life capacity loss towards inertia, disease and death. We require the full framework and coordinates to ground legitimate human rights, obligations and social justice across cultures. This objective and comprehensive framework of universal human life goods and necessities liberates understanding from an absurd ruling culture which recognizes no objective ground of human life at all but self desires, market demand aggregates, and welfare indexes without any principled life-ground. The standard need-set of "food, clothing, housing, and so on" which Marx first recognized 176 years ago after centuries of theory without any life-requirement emerging to attention is a turning point in intellectual history, but still woefully inadequate. It has no criteria, measure or organizing framework of meaning. The ubiquitous "basic needs" invoked by NGO's and others today is essentially vacuous. Average annual income is hardly better. It allows economists to claim a "rising standard of living" in the poor world from an income rise equivalent to a bottle of pop. "Feeding the poor" can mean only processed junk-as in U.S. school lunches where the highlight of food for poor children, ketchup, has qualified as a vegetable. As for the ultimate need of a human vocation - to serve, express and enjoy human life capacities as a coherent end-in-self of value - this core of social justice does not yet exist as a known concept. In short, humanity has been a long time without its most basic life-value bearings, and this absence of meaning fits the ruling order like a glove.

\section{Life-Need Disconnect Across Theories: A Reprise of 2500 Years}

Sound criterial measure of human life necessities is a life-and-death matter. Yet the reigning economic theory everywhere since Adam Smith has confused necessity with market demand. In Anglo-American justice theory as well as economics and studied philosophy in general, no standard of life need ever arises. The concept in principled form might as well be outlawed. John Rawls' famous "primary goods," for example, is decoupled from life needs altogether. The ruling proxy of money "income" substitutes for them even in the twentieth century's reputedly leading work on social justice. Theory in general continues the effective prohibition in the political economy discourses of the Left which track capitalist-system mechanics with no ground of meaning in life necessity itself. One might say there is a pathological block against the life-value meaning of needs in Western civilization-except that Eastern civilization may be more blinkered still. It does not and cannot distinguish between a vital human need and an extinguishable attachment in its Vedanta and Buddhist forms, while Confucianism prioritizes propriety to superiors over the life needs of anyone. Unsatisfied life needs are left as a problem of the lower classes, while the decorum of the rich gives the illusion they are above them. The labour of appearances takes their place.

The great exceptions are Lao Tzu in the East and the recorded Jesus in the West, who speaks of "feeding the hungry, clothing the naked, and giving shelter to the homeless." Nonetheless official culture and lead thinkers normally subjectivize need 
a-priori, and almost never relate rights to defined life needs. Philosophy seeks to understand the ultimately regulating principles of the human condition, but has avoided this ultimate issue from the beginning, most dogmatically since its linguistic turn of the twentieth century. Economics is meant to comprehend production and distribution of otherwise scarce goods for human society to develop, but is blind even to the distinction between life goods and bads. History is supposed to find the deciding ground of what uprisings and forward movements of peoples are about if it is to understand what is going on, but ruling-order provision of life necessities and goods for society and its technological-social possibility remain unexamined as an historical struggle and trend.

Does any social science do better? The general fact is that is that no higher-order theory of rights and social justice grounds in the life-and-death necessities of human existence. Even materialist theories avoid universal human life needs. The ancient Carvaka of India focused on voluptuous desires, and no known materialist doctrine since has comprehended or researched a universal life-necessity framework. Karl Marx brought European ideology "down to earth," but begins Capital by saying on the first page that "the nature of human wants, whether for instance they spring from the stomach or fancy, makes no difference" (Marx, 1986, p. 43). The issue of the life goods all people need to live and live well has been essentially a blank slate except in medicine, and as we know its contemporary dominant forms have been biased towards expensive corporate commodities for profit - exotic machines and corporate pharmaceuticals for symptoms. Even with the new welfare indexes where we seem at last to be getting towards the life base for rights, duties and social justice, there is no criterion of life good or necessity in any. A leading formation of such an index in Canada, The Canadian Well-Being Index, is a case in point. When provided with formal demonstration of the universal needs principle and framework required for any concept of welfare to be life coherent, the assembled experts, in the words of a lead participant, "greeted it with a strange silence and would not engage it." 3 This response symptomizes the ruling syntax of contemporary thought.

Life-value analysis, in contrast, begins with humanity's necessary life goods as its ground. Standard categories like "income," "primary goods," "prosperity," "rights," "freedoms" and so on are discovered under analysis to have no principled meaning of life value at all. One must therefore build from the ground up. Once research and reflection manage to arrive at defining principled grounds of humanity's universal life necessities and goods, life-value analysis can work towards laying bare a unifying framework of them. This has been a difficult road in a cognitive context in which countless varieties of relativism, differences, custom and resistance rule out such a research project a-priori. Again we find there is virtually nothing to work with that is well formed and life-grounded. Yet without such a principled life-ground one cannot truly know what human beings have rights to as humans nor what social justice consists of. The onto-axiological base and substance of what really matters to people's lives and life conditions remain missing. Against this ruling arbitrariness of rights, life-value understanding re-grounds thought and analysis at the level of human life necessities and capacities and, therefore, in the ecological support systems that make them possible at the same time. This is the ecology of life value and justice underpinning the regulating whole. 
Social sciences and philosophy have nowhere yet so grounded themselves. Readers may think, what about Marx? He seems to re-ground in human life needs and capacities, but on closer examination his ultimate base is found to be historical productive force development which he assumes realizes human life needs and capacities and necessitates the revolution of capitalism to full human freedom and self-realization at the same time. Yet Marx and Marxists have never provided lifevalue criteria to explain or to bridge the three levels of life-and-death issue which are skipped over here: (1) why seizure of the state from capitalist control is ensured against the systematic life-blindness of the order it grows out of; (2) what collective life-values there are to guide this state rule and its productive force development beyond more material output as an end in itself; and (3) how human life needs and capacities are to be enabled and fulfilled by this program as assumed, rather than distorted or imprisoned by it.

\section{The Modern Blind Eye: No Life-Value Standard to Steer Productive Development}

Productive force development can go well or badly depending on its regulating value purpose-well if steered by life-value coordinates to realize human needs, badly if steered to maximize private profits or state-party power. In itself, productive force development means nothing but more material output. One of the greatest confusions of mankind is to assume that more productivity or material output automatically means better lives and life conditions for people. Without any life-value criterion to show or enable this outcome, it is pure magical thinking. Consider for example a state-induced flooding of the natural wonder of the Yangtze River Three Gorges into a central power dam with millions of inhabitants who are forcibly uprooted and beaten if they resist this action, and the potential for long-term ecological catastrophe ignored by the ruling engineers of the Central Committee. Under the direction of private money capital, the outcomes can be much worse. More material output with no accountability to any objective but more private money-value to fast-profit stockholders can end in only more job losses, waste, and junk in the world. One cannot, in short, assume that technological advances or innovations in themselves serve human needs and capacities to live fuller lives. They can only reliably do so if life-value standards govern them, and they have never been so governed.

Marx was not as life-blind as classical and so-called neo-classical economics or states run by engineers, but he still supposed life-value advancement by productive force development as the ultimate principle of historical change. His essential justification is that private capitalist control for profit explains the monstrous outcomes. Yet however much this analysis explains, its argument cannot in principle meet the ultimate problem. For life-grounded standards are not only missing, but never formed as an alternative. Without them to help recognize the conflict between human life and life support requirements, on the one hand, and more and bigger material outputs on the other, only the assumption of a better life for people is left to rely on. This has been the deepest onto-axiological fault-line of both the Marxian and the capitalist ideas. What is required to steer the world from its cumulative construction of human-and-terrestrial-life catastrophe has been fatally screened out: the life-coherent use of technology. 
The capitalist story of the private market's invisible hand necessitating the best of all possible results or "optimal" social welfare may be the prototype of the life-blind logic of rule, but whatever doctrine is believed, only life-coherent technological development can resolve the problem in principle, and that requires regulating life standards at both human and ecological levels. The industrial method of factory and assembly-line production expanding to ever vaster and world-changing forms can continue to be either by slave-like mass labour and ever more nature-destructive machines and methods or, at the other pole of possibility, organized by coherent life standards to ensure humanity's universal life necessities and goods including human vocation and environmental integrity of growth. This is the deciding choice process of social rule-system.

The belief that the powers of production themselves "discipline, unite, organize" the working class into revolutionary self-determination and human freedom is one of the still-believed formulae on the left that has blocked the life standards required. For every moment of this discipline and organizing in capitalism is to save private money costs for absentee investors, and to do so by turning all moments of production including workers into life-numbed mechanical functions. Why would people so conditioned become an oppositely-structured force against their conditioning around the clock? Without life values regulatively steering productive forces, the outcomes are not magically arranged by an invisible hand or dialectical laws to be optimal. To steer by life-coherent standards rather than magical thinking is the social choice space that has been lost by both warring parties. The long-term outcome has come to be virtually every life system in cumulative decline. Yet this life-blind automatism still leads at the front end. ${ }^{4}$

\section{The Ultimate Requirement of Social Justice: Re-Grounding in Universal Human Life Goods}

Soviet industrial development showed that the mounting life catastrophe is not only capitalist in nature. It had few or no effective life-value standards at the political and ecological levels. The infamous mass murders and industrial ecocides require no elaboration here. In fact, they have provided the choral chant of capitalist propaganda since. Where states like Cuba or Venezuela in our time have better structured towards meeting basic life needs, they have been made international pariahs by the usual selective reporting for which provision of universal life necessities is blinkered out a-priori. While no thinking person should be duped by the Orwellian clamour, life-value analysis applies to clarify the problem on both sides. Neither Cuba nor Venezuela specifies principled life-value standards to ensure accountability of the ruling party to their realization. Yet Cuba, which has been at its socialist revolution for 50 years in spite of U.S. continuous criminal embargo and violations of international law, has advanced far. In elite performances of conventional forms of sport, music, and dance, free scientific and literacy education to a universal level, and life-serving medical care at an international level of commitment, the accomplishments have been immense. On the other hand, critical dialogical development of public discourses and political policy has atrophied, with locally-led innovation and the common resources to organize better social living 
conditions on the ground absent-such as the poor rebuilding their barrios with stateprovided materials in Chile before President Allende was murdered in 1973 by a U.S.-supported military coup to restore the capitalist market.

Advance or degradation of the human vocation is the key on all sides-the ultimate need for life contribution and enjoyment which entails free critical speech, thought and creative action in realizing the life capacities and needs of people. Here corporate globalization has moved rapidly backwards, cumulatively eliminating the human vocation without noticing it. Even its critical higher education and research, once the leader of the world, have been subjugated to the corporate private-profit mechanism as the next generation has ever diminishing opportunities for any work except private-profit service jobs serving no life need. Beneath rising structural unemployment for post-2008 youth, falling vocational security at life-serving functions across the world is the greatest unseen crisis of globalization.

Life-value understanding therefore proposes a meta shift of rights towards each person's right of access to a universal human life good rather than being confined within the now ruling legal concept of merely private rights to exclude all others from whatever is held. This is a foundational distinction which brings into the light the universal life needs of human beings which have been blocked out in rights and other discourses. Every one of the goods specified in what follows from objective criteria which have been lost to received analysis. Each denotes, that is: (i) $a$ universal good which is (ii) also a universal life necessity, and (iii) holds across individuals and cultures (iv) if and only if, and (v) to the extent that, (vi) deprivation of $N$ (vii) always results in reduction of life capacity. We will designate (i) to (v) the $N$-axiom.

Before identifying the set of universal life needs and goods which frame the issues of rights and social justice for a life-coherent standpoint, there are a number of issues to be considered as one works through them. Every sphere of goods defined ahead is necessary to human well-being by this $\mathrm{N}$-axiom, but to very different degrees of necessity from one good to another. As we have seen, for example, deprivation of clean water is more immediately life-destructive than of environmental goods, but environmental goods are nonetheless necessary to a human life by the same measure. One should also keep in mind that even if most humans alive have not had sufficient access to these goods, it remains true by life-need criterion and measure that they are reduced in their life capacities, even when this reduction is normalized. In official measures of people's welfare, for instance, only an aggregate average of private money-demand is involved therefore more priced goods (commodities) which may be junk or disease-causing are still classified as "welfare enhancing." At the same time, impoverishment in a society's real life goods - its jobs, its environment, its foods, and its natural resources - do not factor in. Perhaps no absurdity has been more ruinous than the private money-demand measures of human well-being and development - more lethally fatuous by far than buying indulgences from the Church to better one's life chances. Yet innumerable false doctrines collaborate in disconnecting corporate, state, popular and academic intelligence from objective life values and so too rights and obligations. Even democratic theory has become ungrounded from what people require to live and live well. With the ruling model as electoral headcounts in a corporate-state field of propaganda, a majority can be indoctrinated to support on cue as "freedom" a belligerent war, or the depredations of young lives as "treats for the children." High theory does not re-ground, however, 
but de-grounds further. Fictitious contractarian models and debates with no lifeground nor organic need-nor mention of corporate profit itself-multiply in journals, books and graduate schools as "the latest research on justice." In opposition to all this, life-value understanding recognizes that real development and social justice advance by better provision of universal life goods and necessities to people without which they suffer loss of life capacity - an objective fact admitting of objective degrees of advance or regression. Theories and practises are thus obliged to face a life-coherence principle of validity - that is, whether their positions are consistent with or blind to the most universal requirements of human life itself.

In short, life-value understanding reconnects to the universal goods which each and all objectively need to live a human life - the missing life-value meaning of the Socratic wisdom that "an unexamined life is not worth living." Whatever creative choices one might make and be individuated by within the range of possibilities opened by access to these life goods, they are required by every human being; and human rights and social justice correspond in development to their sufficient provision. Yet no sooner are such words as "universal" and "necessary" out than charges of "paternalism," "neo-colonialism," "the terrorist universal" and so on are unleashed. In high theory as well as the capitalist market, a conventional thoughtspace of life-disconnect reigns. A useful experiment here is to identify any universal and necessary life good whatever for humanity which is acknowledged as such in the entire literature of contemporary higher-order thought. As perhaps future inhabitants of the globe will recognize in amazement that any life was possible for them after such a global disorder, this system-wide disconnect has become so complete and complaisant that most in governing circles and the academy resist understanding of what is happening even as the ice-caps melt and the next generation cannot find a livelihood or vocation. What is miscalled "the economy" has one supreme law that overrides requirements of life at every level - to turn private money into more money for its possessors ad infinitum through private money-and-commodity vehicles. The mind-lock binding acceptance is that this system is alone capable of "delivering the goods" when, in reality, it increasingly despoils life goods and rights across the world. One can only know this, however, if one knows what these life goods are.

\section{The Universal Life Needs and Goods of Humanity: Understanding the Life-Base of Rights and Obligations}

In the unifying life-value framework of needs/goods defined below, each is a universal life necessity and good because no-one across cultures can be deprived of it without losing life capacity towards disease and death. All are distinct from each other because none can be provided for by any or all of the rest. These general facts may be tested through every one. In life-value social justice, the universal necessity of each confers a universal human right of all to it, linked to the corresponding obligation of all to work for this provision.

It is the greatest if unseen failure of the global corporate market that not one of these universal human life necessities is in fact ensured by its organizing order, and increasingly more are endangered or overridden by it. Indeed because it is blind to 
life necessity itself and depends on producing scarcity to extract private profit, this system is a-priori structured against sufficient life goods provision for society. Whether any of these life needs are met, or are violated root and branch, is a matter of indifference to its value code. Yet provision of these universal life goods, and only access to such life goods, enables the "good life" for anyone. Conversely, deprived of any of these universal life necessities/goods, and to the extent of this deprivation across the italicized categories below, human suffering and social injustice demonstrably follow.

(1) the atmospheric goods of unpolluted air, sunlight, climate cycles, and seeinghearing space;

(2) the bodily goods of clean water, nourishing food, fit clothing, and waste disposal;

(3) the home good of shelter from the elements and noxious animals/materials with the means to sleep and freely function;

(4) the environmental good of natural and constructed elements contributing to a lifesupporting whole;

(5) the social goods of reliable care through time by supportive love, work-day limits/safety, accessible healthcare, and security of person;

(6) the cultural goods of language, the arts, participant civil rights, and play; and

(7) the vocational good of enabling and obliging each to contribute to the provision of these universal life goods consistent with the enjoyment of them.

The reader may independently test this needs/goods index at every point. Two generic questions arise for any sound criterion or definition, and they are worth applying to each and all of (1) through (7) as well as the whole set at once. Is anything claimed that is not a demonstrable universal need/good by the N-criterion? Or is anything missing from the set or any part of it? In elementary logic, these are known as the questions of "too broad?" or "too narrow?" They take us through all the questions and debate required to know the sound answer. This is the process of truth for life-value onto-axiology, the process of more coherently inclusive taking into account. The resting point of valid criterion is reached when there are no exceptions to show that the frame of life-needs and goods above is too narrow or too broad in any category or as a complete set. The process moves through testing counterexamples as long as these can be given, at which point one knows the provisionally sound solution has been developed. If this set of universal life needs/goods of human beings still stands in the face of counter-argument until no life-coherent candidate remains, then it has stood the test of truth.

Once at this point, we recall the principle of measure. Each and all of these universal life goods admit of sufficiency or insufficiency which is definable by the margin gain, or loss, of life range with, or without, provision. Sufficiency is reached when no life good is missing from this set without which life capacities are reduced - a condition that flourishing human lives and societies both enjoy and provide for. It should be emphasised in the face of long confusion and nonsense on this point that socially assured sufficiency of life goods does not mean authoritarian government or levelling of individuation and diversity. The goods are universal necessities of a human life, not dictated by central authority or anyone else. People's lives are not levelled, but on the contrary, more diverse, free and individuated by their assured provision. 
At the same time, the universal ethic and social justice of the general principle "from each according to his ability, to each according to his needs" is provided with what it has long lacked - the precise criteria and right-obligation linkage of its basic terms. While life-value understanding endorses this principle, it recognizes and meets its three fatal problems:

(1) "Needs" themselves have remained without definition and bound. Thus damaging habits conceived as needs may qualify as benefits, leading to disabling consequences and disputes.

(2) The "ability" expected from each is not grounded in human life capacities themselves. Thus dehumanizing use of abilities can be obliged "from each," allowing for distortion of the underlying life capacities they express.

(3) There is no principled linkage between needs and abilities to ensure the coherence of their realization. Thus the ancient division between the unequal abilities and needs of people still remains unresolved.

With no defined criteria of its burden-benefit sides to solve (1) to (3), the fromeach/to-each principle remains only a resonant slogan without directive substance. The principle's greatest advocate, Karl Marx, disclosed the first of its central problems himself without realizing it. He affirmed "need" growth with no limitcounting tobacco and mansions as needs if these were the norm of the stage of productive development of the society in question. At the same time, he uncritically assumed that the productive development conditioning these "needs" was their external determiner beneath choice. What other great philosophies like Buddhism and Lao Tzu's Taoism affirmed as the ultimate choice-space of humanity-release from created wants - was not only ignored by Marx, but overridden by affirmation of human needs without end. Ironically capitalist economics since Marx have assumed non-satiety of wants as the first premise of market growth. In this way, Marx and bourgeois economics agree on perhaps the most ruinous assumption of modern thought. Life-value onto-axiology adopts an opposite stand. It recognizes as needs only goods without which life capacities are reduced. Humanity's economic and social advance can thus be objectively understood by life-value criteria, as distinguished from propagandized without check. At the same time, human rights and social justice are provided with the substantive life content that has long been missing.

\section{Beneath the Recognition of Policy and Theory: Global Corporate War Against the Human Vocation, Civil Commons, and Social Justice}

The ultimate life good of human vocation, (7), is axial to human justice and wellbeing because it links peoples' rights to universal human goods with their obligation to contribute to them. This obligation is precisely not coercive inasmuch as it is answering to humanity's deepest need-to do what is of value to others and meaningful to oneself. This is, most of all, why human beings are more than twolegged animals. Two-legged animals are identical with their self-desires in the 
individual, and are unconnected to each other by rules for mutual life-good provision within herd and peck-orders. This inhuman state admits of degrees, but almost all societies we know today are bound in this direction by the ruling system of all competing against one another for means of existence and private profit for the few.

While almost anyone can recognize by first-person test the human vocation to produce life-value for others beyond self-it is what drives every artist and selfrealizing occupation that exists - this human vocation has long been conditioned out of conscious recognition by the system within which most live. Even in high theory, it gets lost in atomic concepts of "self-respect," as in the Rawlsian and Adlerian traditions. Most deeply, it is directly reversed by the ruling market onto-ethic since Adam Smith which conceives work as a disutility - what one has to sell into another's property to survive. Constructive activity to produce life-value for others as goal — what we are impelled to do if we are healthy human beings-is thus erased or repressed as a form of life and motivation. While it remains in home-making work, teaching and other professions not yet subverted by external money-sequence subjugation, it grows ever scarcer in the global market system. Throughout, revealingly global-market corporations never stop telling us that what they do is for us. They obliquely recognize the basic meaning of human being, but its motivation has in fact been driven into the life-unconscious at both market and theoretical levels.

We already know intuitively that no-one can flourish who does nothing of value for others. This is why people so often pretend that they are when they aren't, why deadbeats wither on the vine, why disemployment causes disease, and why both left and right have long recognized that a large percentage of people without work is a social disaster. On the other hand, the insistent reduction of human beings to manipulatable desiring machines is the onto-axiology of economic doctrine and its ancillary psychological sciences. In his paradigm-setting work, Mathematical Psychics, Frances Edgeworth crystallizes the onto-axiology at work for the first time (italics added): "The conception of man as a pleasure machine may justify the employment of mechanical terms and mathematical reasoning in social science" (Edgeworth, 1932, p. 15). ${ }^{5}$ This concept of humanity as a pleasure machine is a fatal reduction built into the ruling money-sequence and commodity system because it is set to perfect indifference to all life and life conditions beyond priced desire-objects for atomic selves. While purporting to serve people's interests in the most productive and efficient way possible, its life-blind organization has in fact cumulatively hollowed out their planetary life support systems, while leaving an increasing majority without the life necessities they require to be human.

An economy is productive and efficient in fact to the extent that it provides life goods which are otherwise scarce to its members through generational time. What ensures that a society does this, rather than merely produce more luxuries for some and life-means deprivation for the many, is what life-value research designates as the civil commons. The civil commons is amnesiac in this era, but it is the social basis of all valid human rights and social justice - that is, any and all social constructs which enable universal access to human life goods without which people's capacities are always reduced or destroyed. Thus defined as scientific principle, the civil commons can be recognized as the unseen differentia of the species which first emerges in linguistic symbols themselves and distinguishes all subsequent supra-genetic evolution. Lest this moving line of social development continue to be blocked out within the reigning system which dismantles them, civil commons functions still 
sustain the human condition everywhere we look beneath the surface of private commodification. As I sit now in my home, there is nothing I experience and need that is possible without the civil-commons infrastructures enabling it. The electricity flow to my word-processor, lamp and space-heater are built and guaranteed by publicly built public hydro sources, lines and safety regulations including the standard-plug structure and sustained currents whose failure at any point might destroy my machine as well as my projects. Yet even this fundamental necessity of my human vocation, of my light, warmth, cooking and refrigeration could not occur without long civil planning, contribution and struggle to develop and retain every moment of their common life support systems. Here and elsewhere, however, private money-sequence forces dismantle common infrastructures without identification of their causal mechanism of destruction - as the example of New Orleans shows, but does not teach. It could not withstand an offshore hurricane with its stripped civil commons leaving nothing intact in its natural and built sea-delta substructures and community resources of rescue, health and housing. Hurricane Katrina was not a natural, but a system-made disaster-from its background destabilization of hydrological cycles through its thousands of stranded and drowned people to the millions of New Orleans people still homeless or ruined today.

Even with the already long-achieved provision today of what is relevant to the satisfaction of all human needs, the private money-sequence system is structured against sufficient provision. Consider universal electricity generation and distribution, one of modern humanity's great advances in life goods provision. New private-profit control of electricity provision recently bankrupted the wealthiest state of the US, and treated its citizens to endless blackouts and extortionate prices up to 200 times the normal, making the new scarcity it had caused ever more profitable to its agents. That Enron money-sequence managers and sales personnel were ebullient at every blackout in California in anticipation of lavish commissions to them from scarcity prices disclosed the anti-supply bias of the privatized system. Yet until it collapsed, Enron was regaled as a global market leader with its "asset light efficiency of private energy management and supply." Such is the fate of profitizing public infrastructures. Public sectors have, however, much longer built in a civil commons direction. The sidewalks we walk on, the increasingly common pathways for bicycles, the growing gardens and life habitats for public view, the multiplying commons of free-ware and knowledge are civil-commons constructions which advance and diversify against the private corporate tide. I can still breathe the air outside my inner-city home because there are public regulations, also hard-won, on exhaust fumes from private and private-profit automobiles and from corporatefactory pollutions - still poisonous in the big cities, and dangerous even in a small town for citizens with bronchial and respiratory illnesses. So far as they exist, all such life goods and protections are provided free of profit demands and defended by public regulations.

Yet both these civil commons formations sustaining society and the war of private corporate rights against them are without a received theoretical literature identifying the life-and-death forces at work. This is the empty theoretical space which life-value analysis maps to define an underlying struggle whose ultimate stake is the future of terrestrial life itself. Its critical application makes clear what remains otherwise invisible. Consider for instance one of the most basic life spaces of all-the life field 
of hearing which, beneath public notice, has been cumulatively invaded and occupied by private commodity machines across the rural-urban divide. Here as elsewhere, the pattern is familiar but unseen. As a common life good is made scarce by market spoiling, it creates a new market for profitable commodification of what has been deprived (e.g., gated communities and wealthy tourist retreats). Thus the circle of life-value destruction feeds on itself. Only effective public regulation can defend against this spiral downwards by life-protective laws and requirements - for example, mandatory corporate-machine silencers to protect public life space. The civil commons $i$ s this life space and defence at the macro level. Yet now new lifefield occupations occur by massively state-subsidized industrial corporate windturbines which occupy horizons, destroy countless birds and flight paths, and propagate subsonic waves which disequlibriate the autonomic systems of human and other life. Mass-built for private corporate profit at public expense, they require almost as much fossil fuel to build and sustain power outputs as the fossil fuels they are supposed to replace, destroying common life fields on further levels. On the wider plane of commercial energy failures, still more government handouts are extended to leading carbon polluters while the public solution which has worked in past crises of collective life threat, public rations of use, do not enter policy conception. What does not conform to system demands is again blocked out at the level of public understanding itself. ${ }^{6}$

When analysis re-grounds in the life infrastructures of the civil commons, however, it still finds long-won rights of human life which are protected around the clock beneath conscious theoretical and economic conception-not only the publicly produced electricity, water, waste, and regulated oil-gas systems sustaining and protecting their lives, but countless other enforced public norms against assaults and threats, toxins, disease bearing biota, spoilage dates, hidden commodity contents, and so on. Yet as long as they not seen, defended and advanced as the very life-security fabric of society and individual freedom, the civil commons are relentlessly circumvented by private corporate interests and governments serving them. Their sole goal under law is to sell more for private profit. Already these private forces have taken over independent government testing of food and beverage products, smuggled in genetically-engineered contents, sabotaged public efforts to flag junk foods and drinks from local to UN levels, uploaded sugar, caffeine and salt contents to disease levels in even children's drinks, and the like. Humanity's food supply itself has been cumulatively contaminated and debased around civil regulations while global life support systems are more competitively stripped and polluted at the same time. Yet no theory or practise can decode the causal mechanism of life-destructive effects or its civil commons resolution without life-value principles of analysis. This is why the global war of occupation is still called "economic development" and "productive growth" even by Marxian opponents - an example of the inverting group-mind at work in the most unexpected places.

Thus the life-serving social infrastructures which have been built since the nineteenth century are not adopted as a conscious historical base to universalize across the globe: unbreakable laws to ensure the purity and universality of water supplies; open travel paths and lanes across the world for all to use; construction and maintenance of community sewer systems and garbage cycles; inspection, disinfestation, and condemnation of private as well as public structures deemed to be health hazards; the systematic testing, inspecting and screening of hardware products 
to validate their safety for human use and consumption; publicly enforced workplace standards in private factories and places of business; provision of public spaces and paved paths to ensure non-priced free and safe movement for all; development over generations of non-profit public media, libraries, museums and universal learning systems managed by public servants for whom price or profit demands would constitute a criminal offence; and most recently and perhaps revolutionarily, nonprofit-led development of a universal nano-second communication system of information and reliable knowledge bases without price barriers, corporate monopoly or state censorship in the civilized world. Karl Polanyi's classic work, The Great Transformation (1944), perceives the "natural and social life substance" that has been historically market attacked, but identifies no through-line of development of society's common life bases themselves, many of them emerging after his study. His emphasis is on pre-market community and stop-gap social measures. Marx and Marxism focus on the class divisions within the capitalist system with little or no civil commons recognition beyond factory inspectors and the 10-Hour Day Act.

Because conceptions of human well-being and justice in general have long been decoupled from the biophysical world, from human needs and their criterion, and from the contending principles of providing these life means, no theory we know has recognized or defined the common life interest and its foundations. While opposed on the surface, "conservative," "libertarian," "liberal" and "communitarian" schools of theory share these blinkers in different ways. Each may glimpse a dimension of the civil commons, but never its organizing ideas, criteria, and full substance. ${ }^{7}$ The ancient idea of the "commons" is itself radically inadequate because it applies only to natural forests and the immediate natural resources characterizing medieval and remaining village commons. It does not recognize the social construction of their protection and reproduction, nor their more important cumulative modern form of civil commons infrastructures and services for all citizens. In short, no received literature however progressive has recognized the onto-ethical nature and evolutionary ground of civil commons which distinguishes the human condition itself. Thus "the commons" that remain to conception are stripped of their universal meaning even when the term is retained. Transnational corporations see only limitless resources to exploit rent-free, while those who see them as something more still have no criterial ground of their affirmation. The civil commons remain thus open to any block or distortion at the level of meaning itself. Without principled comprehension of humanity`s evolving social life support systems, disconnection from them follows. Who is the historical subject? What can replace the industrial proletariat? What concept of collective agency can we have? The now established box of formal analysis is that economic and political science cannot think beyond aggregates of atomic selves, while philosophers are stuck within an agent-relative ontology where social agency disappears a-priori. ${ }^{8}$ Thus confined to market, electoral and moral aggregates of private individuals, the expropriation and spoilage of common life support systems proceed for ever more private commodities and wastes. With no social subject or life-value ground, shared life supports can collapse all around with no-one accountable for the results. "Impersonal market competition" decides, the supreme alibi for abdication of social self-direction and responsibility. This is the core of the entire failure of contemporary humanity. 
The sovereign demand to be "more competitive in the global market" rules out human meaning itself. Thus new jobs for the younger generation occur only in private money-sequencing functions or sub-functions-from fast-food services to telemarketing of unneeded commodities, from assembly-line training and jobcasualization of the academy, to management services to private money sequences. One master rules as inhuman meta-program. Thus even when the most beloved and recognized civil commons formations - like Canada's public healthcare systemcannot be cut without loss of the next election, the system's inner logic is not understood. Like Plato's cave-dwellers held by chains of conditioning to see only dancing shadows projected onto the wall, the regulating forms behind the changing appearances are not seen. In the wider global whole, the civil commons substructure of society is defunded, privatized in bits and wholes, opened to foreign corporate takeover, tax-starved and stripped back at every level from one decade to the next without connection of the dots. The state itself is reduced step-by-step to two ruling functions which are assumed but not named: armed defence of private global corporations' interests at home and abroad and unconditional government hand-outs to ensure their competitive growth. If their money-sequence overreaching bankrupts them, the corporate-market state re-finances them across the world with public money and strips back social sectors to pay. ${ }^{9}$ The captive state is throughout represented, however, as the opposite to what it is. Increasing hundreds of millions of people can be without ecological security or even water and nutrition as global wealth multiplies in the control of an apical few. Yet the freedoms and well-being of the poor are declared to be rising. Ever greater volumes of junk commodities may undermine the health of children and non-affluent across the globe, but when critical science recognizes the epidemic damages, governments still leave bio-assay responsibilities to private corporate control. Social infrastructures of education, health and pensions may be slashed and privatized to pay compound-interest public debts to private foreign banks, but the transfer of wealth from the impoverished to the rich is pronounced "economic necessity." Public electro-magnetic spectrums may be all privatized for global media corporations to mass produce commercial and violence images, but a "global information culture" is proclaimed. Wars and domestic oppressions by force of arms may dominate public budgets as common life support systems degrade and collapse, but "world security" is declared the ultimate purpose in national and international forums.

Life-coherent analysis does not stop at recognition of the privatized state and its propaganda. It re-grounds in what class analysis of the system does not, the life-blind incompetence of this rule which is objectively demonstrable by life-value parameters which class and systems analysis fail to penetrate: the deprivation of universal human life necessities requirements across society at every level. This is the lost baseline of human society which is unexamined and ungrounded by received theory. Only from it can deep political economy steer beyond the ruling-class state by exactly understood civil commons institutions that demand defence and development now more than ever-for primary example which is hardly discussed, by publicutility banks to lend to the people including a central bank to lend to all levels of government, retaining interest charges in public budgets for further spending back into the economy and issuing credit for common life-interest purposes. This is an already constitutional path of currency and credit responsibility, but it has been variously abdicated by captive states over a long period. ${ }^{10}$ As with sound public 
education or natural resource protection, there is one underlying principle of directive meaning, the civil commons. Only its ground and direction meet the void of theory and practise at this ultimate level of social foundation and change-always bridging from one or more human universal life necessities to universal provision, from common fires, water sources and language symbols to public spaces, hygienic practices and shared life respect itself. The civil commons through-line is the lost thread of humanity's meaning and advance - the human being who decides the laws by which it lives, and who becomes just by the universal life goods in which all of its citizens both participate and enjoy by society's organizing rights and obligations. From this underlying human life code to the knowledge commons of today, social justice is the civil commons process which enables what each and all are due as human.

\section{Performance Evaluation of the Civil Commons and the Private For-Profit System: The Universal Goods of Our Lives and How They Are Safeguarded or Destroyed}

The facts of daily life in developed society have been so painstakingly and historically constructed across generations to enable universal access to the life goods of evolved humanity that, as a result, we need systematic understanding of the comparative performances of civil commons and private corporations in providing them. Beyond the civil commons bases of safe and reliable energy flows into homes to perform the functions required for individual creation, food, warmth, and sleep, beyond the evolving body of public rules and regulations to ensure the safety of clean-and-waste water cycles and building structures, and beyond the publicly built and kept pathways and routes of people's lives in every life-value domain, still more layers of civil commons enable us to live and flourish as humans. The universal education that has taught people how to read, compute and research, the public repositories of books, film and documentation resources which all can access without price, the universal public healthcare without which countless lives are bankrupted, terrorized or destroyed, the universal pensions for old age, unemployment-income insurance, disability allowances and supports, the civil interventions available in countless forms to prevent harms to person, property and home, the public information resources and consumer protection requirements, the public holidays and celebrations of multiple kinds for all, the countless government offices to respond to needs of every kind - where do the civil commons stop?

They stop where they are forced to a stop by corporate-state defunding, privatization, deregulation, tax undercutting, rising allocations to private money sequences, militarized budgets and, most violently in the second half of the twentieth century, by capitalist state wars against societies with developed socialist infrastructures (e.g., Vietnam and Iraq, with prosperous Yugoslavia destabilized in between). Indeed civil commons formations are apt to be equated to "communism" by the mere fact that they are not controlled for private profit-a hate epithet more destructive of human life than centuries of witch hunts and anti-Semitism. Yet what human benefit of culture and civilization do we reliably enjoy that the publicly funded civil commons do not enable for people's lives? And what attack on the civil 
commons is not from private for-profit forces? Here is the moving line of the unseen war against human society itself. The pretext is that civil commons formations are "too costly" to invest in, but trillions of dollars of public wealth are transferred to private banks and corporations which produce nothing of life value as "necessary to keep the economy going." The defunded civil commons by which people's lives and life conditions are continuously enabled on every level is, at bottom, the lost common ground of our lives. Yet from public- grade school education stripped in Africa to pay foreign money-sequence debts to public health systems, and income security for the unemployed, civil services, pensions and higher research in the industrialized world privatized for profit, there seems no end to the reversal of both humanity's very social evolution and the possibility of social justice.

The defining principle of all universal human life necessities and what social justice provides by society's true development is (1) that without which the life capacity of anyone is reduced (2) by the degree of the good's necessity, (3) to the extent of its deprivation when (4) the means are available to provide it. This is the exact line and measure between social justice and injustice across life domains. The universal goods which are provided or deprived are, in turn, goods which have: (i) have intrinsic value so far as they are felt and conscious to human being (e.g., the air, environment and fellow beings felt as values in themselves); (ii) have instrumental or ultimate value without which human life is reduced or destroyed by degrees; (iii) mark systematic injustice to the degree of their necessity, deprivation, and life loss without them; and (iv) mark social justice to the measure of the protection and enabling of their provision through time by (v) society's system of benefits and burdens progressively ensuring their provision. Once social justice is thus defined with principled life coordinates, we are able to understand how it is in fact won or lost in the world: for example, by potable and waste water cycles, literacy levels, social security programs, and accessible time, play and creative opportunities for gains or losses of citizens' life capacities through time. At this point it is worth reviewing the fate and trends of all the universal human life necessities and goods under corporate-market rule. It is here that we can define the destructive lines of corporate invasion of humanity's life fields and conditions in the name of "development" and "prosperity."

(1) The natural atmospheric goods of breathable air, open space and light are not conserved nor protected by the corporate-rights system, but systemically depredated insofar as (i) the air is polluted by its commodities' production and uses (e.g., ever more motor vehicles for profit with no limit on their numbers or ration of their use on land, air or water); (ii) open space is cumulatively occupied by these same private corporate uses and commodities disabling people's lives (e.g., by pervading fumes and motor-spike decibels and subsonic propagations); and (iii) the light of the sun has been made toxic by corporate-commodity effluents having cumulatively destroyed the ozone layer for protecting the earth from infra-red solar radiations. On the other hand, where public regulatory interventions have been prevailed, there are air-pollution abatement measures, open-space protections, and sun-radiation buffers (by ozone-layer protocol, the sole life standard in transnational business treaties). Free corporate use of the universal atmospheric goods of breathable air, open space and natural light is, in all, totalizing in despoliation without public authority effectively regulating every phase of its cycles. As with provision or deprivation of 
all the universal life goods of (1) to (7), human rights and obligations or their violation follow, along with social justice or injustice.

(2) The bodily goods of clean water, nourishing food, and waste disposal have been increasingly depredated by reigning corporate rights and commodity cycles insofar as: (i) the fresh waters of aquifers, lakes and rivers are polluted and drawn down by corporate activities of manifold kinds from factory farming, toxic discharges across industries and commodity extraction, with untreated public sewage itself led by these open-waste methods and by corporate blocking of taxes required to resolve the problem; (ii) the world's foods and beverages are increasingly sugar-saltand-oil laden, chemically adulterated, and genetically contaminated to serve moneysequence functions of mass sale, masking of age and quality, and care-cost reduction, thereby leading multi-disease causation and depletion of seed stocks, vitamin yield, forest covers, and organic immune resistance; and (iii) massive waste methods increase by non-selective forest and fish stock looting, throwaway products and packaging, and non-recycling of waste products.

(3) The home and habitat goods of shelter from the elements and noxious animals and insects with means to freely function are improved in countless expendable conveniences, but under the ruling corporate system: (i) a home is dependent on private money stocks or debt-servitude to private banks at compound-interest charges exceeding principal and, simultaneously, tied to private-developer profits so that increasing numbers of families are home-insecure or homeless; (ii) corporate "development" is pervasively sited on shrinking farmlands to exploit their already historically developed life capital of cleared, graded and drained lands for what maximizes its external money gains; and (iii) protection from noxious animals and insects is by profitable commodities of instant poisons, solvents and other killmechanisms which are hazardous to life forms in general and blinker out lifecoherent methods of public resolution.

(4). The built and natural environmental goods of surrounding elements and contours contributing to the whole are what form all pleasant human surroundings across cultures, but this environing life good also requires public coordination and control which private developers and financiers have displaced: (i) by massive ungreen urban sprawl "development" around one town, city, and beauty space to the next across borders, if not over-ruled by externally enforced regulations (e.g., old European towns or public parks); (ii) by buildings determined only by corporateperson profit for unit sold and not for their contributing place in the whole unless regulated by such public standards; (iii) leased public lands and resources to be torn apart and polluted by private corporate looting of forests and minerals, military attack or practice areas by high-profit weapons, and private commodity noise machines multiplying in number.

(5) The life-protective goods of civil life security and healthcare provision when ill are the mark of civilized humanity in all places and times, but are undermined by corporate-person rule insofar as: (i) the private money-sequence system it presides over redistributes public wealth and worker wages to its own global growth, thereby depriving increasing majorities of civil commons and income security; (ii) the mass sale of addictive and life-disabling junk drinks and foods and the injection of toxins and carcinogens into commodity cleaners, consumables and personal care products which afflict countless people with diseases, whose cause by these products is 
unresearched or undisclosed; and (ii) the privatization for profit of health-restoring goods so that what does not serve corporate money sequences is ruled out, including public health plans and their extensions.

(6) The universal human life goods of language, music, art, and play which constitute culture in all its diverse human forms are debased or eliminated insofar as corporate money-sequence growth selects for funding and reproduction of only those forms which directly or indirectly produce and mass-market commodities for corporate profit. Whatever does not serve this ulterior goal is not funded or, if integral to people's lives, distorted into a form that does (e.g., public education tailored to the demands of corporate rule). Thus culture becomes commodified to sell corporate brands, communication is reduced to what promotes sales by instant images and sound bites, and public cultural policies are determined by corporate modes (e.g., publicly financed spectacle sites in place of community play and performance areas). The cultural form is decided as "good" or "bad," in turn, by private money-value returns - that is, how much is paid for product or reproduction (high art), or how well it sells corporate commodities (commercial art). In general, culture becomes funded or defunded as it returns higher or lower money value to private parties. Students, for example, are required to "invest" in their higher education by debt contracts with private banks to pay for "the higher returns" of their learning - the money sequence of value imposed on and regulating education itself.

(7) The good of human vocation is the ultimate life good for human beings in community insofar as it enables and obliges people to contribute to the provision of universal life goods consistent with each person's enjoyment of them. The logic of rights and obligations here follows from understanding the nature of these universal human life goods themselves. To enjoy the atmospheric goods of nature obliges one to not degrade but preserve them. To benefit from the bodily goods of clean water, nourishing food and waste disposal requires that each contribute to their provision by sustaining taxation and participation. In a similar way, the universal human goods of home and pleasant environment, civil safety and care when ill, and enjoyment of cultural goods are realized in terms of the same logic of human vocation and social justice across differences. At the highest level of abstraction, the vocation of each individual is to do what s/he can that is of life-value to others and of life-interest to self. For none to shirk the duty of giving back in to what enables the humanity of each is the obligation in return for these rights-the human ordering of social justice. These are the true bases of self-respect and freedom. The value of such work for others, in turn, is defined by its contribution to the provision of the universal goods each and all require to live as human. The autonomous artist is not an exception, but an exemplification of giving of the self to provide the world with a great life good, a transformative human creation. One can be a clean-up worker, or an academic, or both in life-time given, or any other number of life-time contributions to the provision of humanity's ultimate life goods. Mothers count as much as farmers who count as much as heads of state in this human ecology of vocation. The commensurable unit of obligation is hours worked for provision of the life goods needed. In systemic contrast, the private for-profit corporate commodity system increasingly results in more permanently unemployed, more downgraded jobs, more extended laid-off periods, less sustaining incomes, more squeezed-out work, more eliminated life benefits, ever fewer people with work pensions, more 
despoiled natural and built environments and-perhaps most ruinously-rapidly dwindling life vocations for the young.

\section{Contemporary Justice Theory Fails to recognize Any Common Life Interest}

While contemporary justice theory has become perhaps the most active field of philosophy in recent decades, it remains within the ruling disorder. Any life-value ground or goods of justice remain blinkered out, and the reigning money-sequence itself system is off-limits to discuss. The substance of both justice and injustice is thus abstracted out a-priori. The central issue becomes, instead, one of money-value "incentives" to "the talented" to "serve the least advantaged"- a logic of justice that is introduced by John Rawls' canonical A Theory Of Justice (1971) that produces most of the churning industry of Anglo-American philosophy on justice. The lifeand-death problems confronting humanity are thereby screened out within a myth of the ruling ideology - that the primary inequality of money gain is based on personal talent. That money-possession differentials do not in fact come from the "superior talent" of individuals, but from the private control of money issue and money capital, is the underlying social structural issue that is ruled out from discussion. The question is not permitted to arise, however, as review of the vast literatures on "the difference principle" confirms. The examples used are revealingly selective and disconnected while politically correct at the same time. A paradigm example is the pay for superior performance necessary to get a woman surgeon to do the high surgery she can rather than the gardening she prefers. On the basis of such dubious examples, necessary money incentives to the talented stand in as the central problem of social justice.

The general principle from which these hot-house debates are generated, "the difference principle" of Rawls' A Theory of Justice, is that "the higher expectations of those better situated are just if and only if they improve the expectations of the least advantaged members of society." While Rawls and justice theory appear here to propose a high standard, the ultimate questions of social justice are blinkered out. The ground of private property itself, money-capital right to become more with no burden, natural resources left over for others, the non-waste obligation, the protection of common life support systems, the production of means of existence, the rights and duties justly assigned to ensure their provision, and how humanity is to live with Nature so as not to despoil it-all of these issues are abstracted out apriori. Critical discussion, instead, turns on how inequality of the income of the "more talented" can be justified. At the highest level of generality, all substantive issues of life-coherent justice are thus erased. The implicitly cordoned-off areas of discussion are worth identifying to comprehend how this framework of analysis of social justice pre-consciously conforms to the ruling money-sequence program. However basic their importance to our lives and their right regulation, the following foundational areas of concern disappear from view a-priori:

(1) the biophysical world itself and its universal requirements of reproduction;

(2) human needs, their nature, criterion and universal structure; 
(3) production of the means whereby societies live, and its organizing principles of regulation;

(4) the nature of actual money-capitalist society and its money-profit sequence;

(5) the conception of any of (1) to (4) as normative issues or questions;

(6) any right or obligation of justice not based on contractual agreement of atomic individuals;

(7) any resource to repudiate any social regulator as evil;

(8) any allowance of method to ground in or introduce (1) to (7) as what must be addressed by a theory of justice.

"What is left that matters?" one might ask. This is a question that does not arise. In this way, all the real-life problems of social justice are screened out by the unseen syntax of argument itself. The universal human life necessities and goods, the natural life-ground and the human vocation are all excluded from this meaning and value structure. At the same time, the actually ruling capitalist system, its money-sequence logic and despoliation of common life support systems are as effectively removed from discussion as if they were taboo to name. The reigning philosophical vision of social justice is, accordingly, a-priori life-blind like the ruling system. They are both governed at different levels by one meta-structure of meaning in which none of these issues can arise. From the start, discussion of "the difference principle" is linked to the life-empty standard of "Pareto optimality," a touchstone of modern social and philosophical sciences. Although Pareto himself does not define the principle in natural language, it means a condition in which no-one can be made better off without someone being made worse off-with no coordinates of life meaning entering conception. Against a surface appearance of fairness, the Pareto principle is in fact consistent with the most extreme immiserization of the majority. For example, if the given distribution is a small fraction of society possesses most of its assets, Pareto "optimization" would leave all their wealth intact with no redistribution because this would make the super-rich "worse off", and thus be a violation of optimal Pareto efficiency. Rawls recognizes a problem here, but shifts it to the deplored feudal past. "It may be that under certain conditions," he says with emphasis added, "serfdom cannot be significantly reformed without lowering the expectations of some representative man, say that of landowners" (p. 12).

Former Marxian scholar, G.A. Cohen, goes with Rawls to the Pareto principle in Rescuing Justice and Equality (2008), but he too rejects it as inadequate for justice. Both he and Rawls, nonetheless, entirely sidestep the capitalist world reality of allocating money to money-capital profit without limit or desert. This is the unstated requirement of Oxbridge-Ivy League respectability. Global capitalism is off-limits to discuss without saying it. Indeed none in this dominant discourse ever engages this actually ruling structure. Since the elephant in the room is not there, its trampling of human and ecological worlds never enters as an issue. As Antonio Gramsci has observed, hegemonic ideas never touch the essential core of ruling economic relations. While standing against any inequality, Cohen declines as well to question Rawls' position that inequality-producing incentives in fact $d o$ get people to produce more real goods from which the poor benefit. Instead just-so stories continue to stand in for reality. There are specially talented and productive individuals, they alone can produce what people need, and the issue is whether to give them higher money incentives to induce them to provide their superior work. Life-coherent reason does 
not go down this primrose path. It observes there is no criterion of need here, nor account of the productivity of the higher paid, nor sound correlation of incentive to either. All of this is taken for granted by the ruling myth which is never challenged. What is not reflected from the wider world is any trace of the actually ruling system of inequality to which no part of the myth applies. In the real world, it is not talented individuals receiving more merit pay, but a financial sect's control of money sequencing to more private money with no productive merit required, and at steeply rising costs to the majority's lives and their common life support systems. The actually regulating structure of injustice is, thus, pre-empted from view to attend solicitously to the myth.

With life-value, money-capital profit and the common life-ground all unspeakable within this disconnected framework, the multiplying assumptions at work construct an ideological illusion which is uncritically reproduced across the world in "justice theory" itself. Money inequality is correlated with superior persons and their performances of value for others - the ultimate alibi of the system. Its popular version, which Rawls emulates without notice, is: "the rich create a larger social pie from which the poor benefit." The man behind this idea in the academy is Pareto, the leading mantra-name in rational choice theory. His position is worth briefly visiting not only because Rawls and Cohen do not, but because it discloses the pedigree of the principle from which the reigning discourse on justice comes. To begin with, Pareto's (1971) canonical Manual of Political Economy itself repudiates any equalizing mechanism as economic nonsense. ${ }^{11}$ It is only used "to get rid of one aristocracy and replace it with another (p. 93), with aristocratic rule as "what always exists" (pp. 311-312). It is a law of nature which only "decadent" and "degenerate" members of the ruling class oppose, he says. These "decadents" are only moved by a "morbid pity" or because they are "eager for perverse enjoyment" (Pareto, 1971, p. 73). Pareto thus affirms war and the mass killing as necessary to "European civilization" whose advance he regards as "the fruit of an infinite number of wars and of much destruction of the weak-[by whose] sufferings the present prosperity has been acquired" (Pareto, 1971, p. 48). "Very moral civilized people," he asserts, "have [also] destroyed and continue to destroy, without the least scruple, savage or barbarian peoples." All the "so-called liberal professions [medical care and education, for example]," he declares in implicit pre-emption of any compensating services to the poor, "derive their income from factory owners" who would be deterred from producing wealth for society by such "humanitarian absurdity" (Pareto, 1971, p. 304). We may see in Pareto the core intellectual program of the global corporate system of rapacious greed which economists justify as "Paretooptimal." While it seems paradoxical that liberal egalitarians would appropriate Pareto to their apparently opposite cause, there is less paradox than first appears. Pareto's principle of "equilibrium," as he calls it, in which none can be made better off without others being made worse off-is a logic of status-quo adhesion. It is consistent with the most extreme and growing life-value deprivation of the majority in the name of a bigger pie.

This is where the Rawlsian difference principle seems to ensure fairness and justice where the Pareto principle does not. Yet when we examine it more carefully, we find that it has no criterial limit on justifiable inequality to ensure that it is not as permissive of the inequality which the capitalist ideology of "trickle-down" has 
justified since Rawls' famous A Theory of Justice was published. In fact, almost every capitalist gain-scheme advocated in the world in these decades-global free trade and investment without borders, ever lower taxes and regulation, "right to work" breaking of unions, and so on-has been similarly represented as a "policy to benefit the poor." Now the IMF calls its breaking of debtor-countries, "poverty alleviation programs." With no life-value standards, people's life necessities can be systematically degraded and deprived to enlarge money circuits, and so long as average income rises a few cents for the poor, justice is seen to have been served. Consider here subsistence farmers driven from their farmland, their family and their community supports into the city - as hundreds of millions are every decade by these "development programs" - with the price of a cup of coffee in new average income counting to the ruling value metric as "millions lifted out of poverty." Where does justice turn? Only by grounding in a defined set of means of life universally necessary to human survival and flourishing is the problem soluble, with civil commons the process of building social justice in life-coherent terms.

\section{Beyond Masking Myths and Equivocal Equality: The Need to reset Justice Theory to recognize Global Injustice}

G.A. Cohen's Rescuing Equality and Justice is the most egalitarian opposition to the Rawlsian "difference principle" within the dominant academic discourse. Yet all the life-blind exclusions identified by (1) to (8) above still govern his understanding of social justice. Criterial life substance, basic needs, and existing ruling social structure continue to be blocked out a-priori. The worst-off are therefore not better recognized in what makes them badly off. The reigning order of wealth allocation by unearned capital income is never mentioned. The masking myth of personal talent reaping higher pay (benefit) for superior productivity of performance (burden) remains in place unflagged. Again we may see the ruling value syntax at work. Thus even radical egalitarian argument here avoids stating the life goods making anyone's life better or worse, blinkers out the money-capital governance of the world producing the deepest real inequalities, and accepts the idealizing equation of deserving more money for superior performance as the ultimate issue to argue about. Conceptions of justice and injustice again disappear into the terms of the masking myth, while the ruling money-sequence syntax remains untouched.

Yet what could be wrong with "equality" as one's standard to uphold against any inequality, as Cohen does. What is not addressed is that the normative category of "equality" allows for limitless exploitation of its ambiguity of meaning. This is why "equality" has been at the forefront of system-justifying doctrine since John Locke and the U.S. Constitution he inspired, while also being a rallying cry of radical oppositions from British Levellers to the French sans-culottes to socialists today. It is an equivocal concept which brings out whatever discussants project onto it. This is why market capitalism has been long described as a system of "equality" and a system of "inequality" at the same time. Even when one seems to have a straight-on disagreement in principle-for example, G.A. Cohen opposed to Robert Nozick opposed to John Rawls, the list is long - the most apparently inegalitarian position like Nozick's is itself a demand for equality before the law in property protection from a redistributive state. "Equality of rights" is thus routinely proclaimed even if a 
growing number have insufficient food and housing, live in garbage-strewn slums, and are functionally illiterate. Until analysis gets underneath the equivocal category of "equality" to what people actually need for their lives not to be deprived, the slogan prevails even in theory. On the ground, the most basic common life goods can be despoiled beneath recognition as "more equality" in both market competition and mass consumption. Consider the human food system itself which has in these names been globally stripped of nutriments by ever more price-reducing factory-farming monocultures, chemical-genetic concoctions and sugar-salt foods to equalizing malnutrition and obesity. ${ }^{12}$

\section{Re-Grounding in the Missing Life Base}

The most basic onto-axiological principle in the dominant theoretical discourse is itself ungrounded in life value, with a "rational plan of life" as the given frame of good for anyone. Contractual justice theory and moral philosophy presuppose this frame of conception as an ultimate good prior to choice. "Communitarian" justice theory does not, but its base is established social relations with no way beyond these constituted attachments to more life-coherent forms of vocation and social order. This is why liberals reject "communitarianism" for open "rational life plans" of individuals. The underlying life-ground is not touched by either. The ideological debate is waged within the parameters of the reigning system, and the logic of life value and civil commons is a-priori abstracted out. No-one in this industry of debate appears to disagree. Yet what of those who have no such "rational plan of life," but reject it as a careerist closure to the creative openness of human being? Young people in particular find elders insisting on such a life plan as oppressive bores, and experience any force-fitting of them into such a "rational plan" as an injustice to their lives. Yet such considerations cannot enter because the young are excluded from this scheme of justice as young. Rawls is clear that their elders must choose for them, and this is not seen as a problem although it may be the upbringing source of all the others. ${ }^{13}$ Yet the young are not alone. Consider the possible exceptions to this presupposition of justice. Giving one's all to the challenging tasks at hand can make the "career plan" a cramping, egoic distraction. An all-round life may rule out a "life plan" as a one-sided reduction. Still the "rational life plan" remains a premise without an argument for it. In practice, the "rational life plan" means in fact a selfmaximizing financial plan - not only a career across decades of unpredictable self, age and world changes, but one within private money sequencing in the global market as the ordering of one's life. What is not noticed at any level of this framework of "rational life plan" is that the good of life itself has silently disappeared. Life as ground, ultimate value and connectively guiding goal is simply abstracted out.

At the same time, world movements for social justice-whether for "basic needs fulfilment," climate justice," "end the war," "food sovereignty," "no privatization of water," "public health not private profit," or "no blood for oil" - cannot compute to the dominant paradigm. Reflect on the contrast between justice theory that is structured to screen out these issues that move people across borders and a lifecoherent understanding of justice that speaks directly to them. The profoundly 
unresolved issue of exactly what is due on both sides of the right-obligation ledger is only answerable by understanding the means of existence which all humanity requires to live a human life, and the social structure and agency whereby these are to be provided. This is why life-value onto-ethics defines these life means and goods with exact criteria, and comprehends the civil commons agency and life-coherent rationality required to enable them. It understands social justice on the ground, in turn, as an historical process of society's achievement of universal human life goods for all by its social rule-system - in the most comprehensive sense of these goods, from natural capital preservation and the coordinated capabilities of scientific technology to life-protective imperatives and universal education and social security. The need/good of human vocation in particular is recognized to be the life-coherent contribution of each to these life goods to receive the benefits and enjoyment of them.

This linkage of right and obligation at a system-wide level is in fact the ultimate onto-ethical issue of human civilization, and requires any system to be accountable to enabling these universal human goods as its measure of legitimacy. When we stand back to consider the historical pattern of the last 80 years, for example, we are able to recognize the meta logic of humanity's universal life necessities/goods and their evolving civil commons provision since the Great Depression and War, on the one hand, and the private-profit corporate war upon them to appropriate and dismantle their resources for private profit since 1980, on the other. This meta conflict explains why ever more growth of wealth by the rule of this system goes along ever more impoverishment of most people's lives and life conditions. This is the unseen war of social injustice - that is, ever more unnecessary suffering from life capacity reduction by deprivation of life goods.

Life-value understanding therefore recognizes and stands for the missing life base of social justice and human advance-the age-old process of civil commons building. Thus, for example, it understands that national public healthcare which became socially provided without price barrier for all those in need of it was a major civil commons victory for social justice in many societies, just as public water and sanitation systems were a century before and still are today in much of the world. In the private corporate rule of the US, in contrast, it recognizes that citizens are ruined or bankrupted by medical costs more than any other cause, and that far more people than the population of Canada are without protection. It understands too that even long-successful public health systems are endangered by the same private for-profit corporate forces which invade civil commons in all spheres in the name of "freedom of choice" or "new efficiencies" or other demonstrably false claim. Yet even in progressive forms, social-structural analysis still reduces the struggle to one of waged workers against capitalism or women against patriarchy to go on missing the underlying common life-value ground. Consider here the jobs and benefits of universalizing literacy as well as public healthcare, society-wide water and sewer systems as well as life-protective laws and norms, life security in old age and disability as well as in unemployment, scientific understanding normalized as well as public play and art areas, open internet communication and information as well as public parks and historic squares and streetscapes - all the civil commons spelled out in prior pages. Yet while there is no level of our human lives and conditions not enabled by them, they remain invisible as common property - not only drowned by saturating devotions to private-profit commodities in the mass media, but not 
penetrated either by economic-classism which blinkers them out in principle. While life-value understanding, the civil commons, and the life coherence principle in fact underlie all authentic human advance, their ultimate ground of meaning and value is not comprehended. As with the amnesiac on the individual level, society's deeper life bearings and human identity have been lost to consciousness.

\section{The Corporate System versus the Civil Commons: The Inner Logic of the World War}

The global disorder is glimpsed in everyday symptoms, but not in the deep-structural conflict itself-the war on common goods for human life by unliving and unaccountable corporate persons. We may sense the soulless mega machine behind the undoing of the world whose symptoms erupt every day, track capitalist class machinations, or merely intuit a system thrown out of joint. But that it is a-priori lifeblind and selects for every life-system attack that humanity is now confronted by is not decoded as a value program. Backed by law and armed force with alias names, no borders of place, no duties but to money profit and no death limit, the private global corporation and its limitless morphs into new forms is in principle inhuman by this program. Its moving human parts and victims no more matter to it than the public subsidies propelling its ever more gargantuan global mechanisms matter to captive states. There is much room for pro and con slogans here, but analysis needs a criterial definition of this constructed mechanism so that we do not remain lost in rapidly changing effects. Its meaning is complex, but can be exactly framed in formal terms. The corporation is a changing pool of money owners defined by a unitary legal goal of profit maximization for its shareholders and their non-liability for the corporation's actions. It is also the sole right holder as "the investor" in transnational treaty legal mechanisms whose rules since 1988 govern the global market and whose articles exclude all labour and citizens rights. Above the lines of natural life and death - "lacking both a body to be kicked and a soul to be damned, they therefore do as they like" in the words of British Lord Chancellor Turlow (1731-1806) - the corporation is the sole agent inducing obligations in contemporary international trade with a unilateral rights to sue governments for "loss of profit opportunity" through binding and punitive tribunals with powers of unlimited financial penalty. In domestic law, the private corporation writes its own charter of incorporation as distinct from its original reception of power by sovereign government conferral.

This deep structure of rule is blocked out across disciplines and cultures, most of all as the collective agency behind the cumulative and systematic destruction of global life itself. While its surface expressions and human manifestations are infinite and pervasive, all conform to one syntax of rule. The subject is private money capital whose verb is seeking to become more without upper limit, and all modifiers are money-demand or its equivalents. Competing money-capital subjects purchase, exchange and dispose of human and natural resources, commodities, and stock futures to become more money capital and commodities as final end. Rationality is, in turn, regulatively presupposed as (i) self-maximizing strategies in (ii) conditions of scarcity or conflict over (iii) desired payoffs at (iv) minimum costs for the self to 
(v) win/gain more. One can see that this syntax of meaning and value is what no human being is - life-value blind in every dimension - but the causal mechanism of disaster it forms is not recognized nor examined, even in philosophy whose formal paradigms of rational justice and morality simply presuppose (i) through (v). Yet what systemic injustice and violation of human and ecological life systems today is not driven by globalization of this syntax of value in money-value terms? The question is not asked, but its answer discloses whether or not any other causal mechanism can explain it. Formally represented again, this ruling system of rights has disconnected its private money sequences from even the tangible products of classical industrialization in $\$ 1^{\rightarrow} 2^{\rightarrow} 3^{\rightarrow--} \mathrm{n}$ sequences of merger and equity predation, currency speculations, shorting bets, price arbitrages, carrying trade margins, derivative covering, credit swaps, and so on. Private money-value multiplication decoupled from any commitment to life goods production of any kind captures government revenues formerly available for investment in social life goods and regulatory structures and increasingly dominates all levels of the world system.

While many blame personal moral defects for the disorder - there is a profound tendency of human thought to personify - the problem goes far deeper into the built laws of the system itself. The turning points go back to U.S. court decisions that effectively prescribe corporate avarice against higher motive of business. For example, in a paradigm- setting state Supreme Court decision (Dodge v. Ford Motor Co., 204 Michigan 459 (1919) the Court held in a precedent ruling that has not since been overturned that it is a violation of "the lawful power of a corporation" to decide anything not "organized for the profit of the stockholders." Here even Henry Ford's own plan to "employ more men, to spread the benefits of this industrial system to the greatest possible number, to help them build up their lives and homes" was ruled against the law. It transgressed the rights of corporate stockholders to maximum profits revenues to themselves. In short, the corporate person could not plan for the life benefits of anyone, even "the greatest possible number" of real persons, without violating its legal purpose of private money sequencing to maximally more for money-stock investors. The corporate person remains programmed by law to this one overriding goal in exclusion of providing more life means for more people by stillprofitable business.

The resolution may be expressed in one life-value principle. Transnational corporate-person rule by money sequencing as the sovereign driver of world society must be regulatively reset-however this is done-so that goods are selected to sustain rather than predate social and ecological life-support-systems. State or capitalist control makes no difference except as they do one rather than the other. The civil commons principle identifies this required ordering. Yet it must first be distinguished from the age-old concept of "the commons" which is used today in profoundly contradictory ways - "global commons" open to corporate-right despoliation or shared life goods of local communities. This confusion is as cooptively lethal as "civil society" - what in fact denotes private property holders, but is now whatever its users assert on opposite sides of meaning.

The global crisis is hinged on the language by which people think and act, often comfortably on both sides of the fence oblivious to the burning issues blinkered out. The actual "commons" were and remain nature-given forests and fields in which villagers graze their livestock, draw water, pick plant-stuffs for food, and access wood and plants for fuel and materials in accordance with their regulating customs. 
They were not, as famously misunderstood in Garrett Hardin's "The Tragedy of the Commons" (1968), natural resources which local people spoiled by individual exploitation. Before they were expropriated by the first agribusiness interests in Britain - the war goes back over centuries - they were structured by community rules for their community protection and reproduction through generational time. Harden's article projects agri-business over-exploitation onto its victims, a familiar operation of the ruling ideology. In truth, the meaning and substance of the civil commons goes far beyond what is given by nature, and is opposite in regulating meaning. It includes all human-made goods that people need and to which community members have universal access by social regulation of production and use. From the earliest times on, civil commons include community abodes and lifespace, structured water sources or wells, care of the young and ill, repulsion of external attacks, human waste and burial routines or rituals, community stories, and tribal languages, sacred symbols, arts and games. Readers may observe that so rich and broad are these constructed common fabrics and infrastructures of human life across the ages that any list always opens to new dimensions. As with other rigid designators of generic qualities across numberless differences and creative possibilities, the civil commons are pervasive in their variety of expression, but contingent on social development of rule-systems -the defining feature of the human species' evolution which is open to reversal or advance, to systematically disabling as well as enabling forms and turns.

Thus virtually every form of the civil commons is now predated and displaced by the global corporate-rights system of rules, but beneath social recognition. What is not comprehended is not protected. Yet the unseen organizing order of the civil commons is exactly verifiable and defined in principle as (i) the social rules of access or activity or production which (ii) enable the access of all members to (iii) life goods whose generic criterion is (iv) that without which human life capacity is always reduced. Confusion, however, goes both ways. What is thought to in the common life interest and even revered as such is often the opposite. We can tell this by the fact that the alleged good does not qualify under these criteria and may maximally violate them-for example, armed-war aggression on distant societies promoted as "defending our country and our freedom." The civil commons criteria, in short, provide the missing objective grounds for distinguishing what has not before been reliably told apart-government and private-sector formations that serve the common life interest versus ones that do not, but pretend that they do. In the longer pull of history, the civil commons principle also tells in every case traditions and norms worth preserving from those better left behind. Without this ultimate principle of normative validity, any confusion can reign, and has done so. For example, an endless politics and ideology of invalidation as "socialism" and "communism," on the one hand, or "unaffordable," "not working-class centred" or "unrecognized in the literatures," on the other, has fatefully blinkered out comprehension of humanity's advance of universally accessible universal life goods in our era from historical backgrounds of natural scarcity, perpetual fear and misery, and arbitrary individual death-just what we see rapidly rising again in global market capitalism today. As always, the life-blind ruling value syntax prevails by screening out the common life-ground of its subjects. Received political and economic understanding are indicators of the instituted mental block at work here- 
as unconsciously biased against recognition of the civil commons as received prejudice is against recognizing the human in other races.

When the dramatically lower life-costs and money-costs of public life goods are compared to private money-sequence rule by corporate persons, however, we can discern the ruling interests behind the established blinkers. For this reason, the efficiency, durability and good management of non-profit public infrastructures and common goods are unconsciously taboo to observe, inverted by the ruling system ideology into silly stereotypes like "Marxist" or "nanny state," or otherwise discounted and silenced. That social versus corporately privatized healthcare, water provision, higher research, communications, shareware, and mass transport have proven far superior in life-enabling outcomes and profitless cost efficiency is thus off limits in dominant public and academic discourses. Yet where does this system superiority not hold? Modern public enterprise in accordance with the civil commons principle is an incontrovertibly more evolved and proven system of production and distribution for the wellbeing of citizens' lives in all areas in which it has been permitted to openly and democratically develop. When we consider an exception sector, such as the greening and flowering of people's private homes and gardens in recent years in advanced communities, we find that it is yet another example of the civil commons principle. All who pass by such homes and gardens are able to enjoy their biodiverse life and beauty without charge or profit, along with community vegetable and roof gardens restoring real growth to grey urban worlds. Even the pervasive corporate pesticides and herbicides sold into this community greening come to be banned by public struggles for the wider common life goods of non-toxic air and earth, which represent the civil commons at the most basic level of natural life support system protection.

What then of factory production which provides machine-made mass goods? They are the great productive achievement of capitalism - but not when they systemically deplete and destroy human lives, ecosystems and natural resource bases, produce nothing of life value, and wasting whatever does not cost money to money-investors for profit. This is the structural derangement intrinsic to the system where civil commons constructs are most necessary of all-to regulate the machine-good economy to be life coherent. This process was in fact incrementally occurring in advanced societies until the global market mechanism was treaty-imposed by lead corporate states as a-priori life-blind. What is missing is the civil commons steering mechanism, compass and life-value coordinates which this system must have if it is not to continue its global ecogenocide in motion. Yet there are now no unifying principles or even name for the life standards and common agency required as the deadly system destabilizations rise towards global life-ground collapse. With only factional splinters and causes seen or reported, the great common interest and agency on which human and planetary life now depend remains effectively unconscious.

Meanwhile corporate-system drivers of deregulation, privatization, lower taxes, corporate-right trade fiats, military spending and foreign wars as well as trillions of public dollars given to private banks and public austerity programs to pay for them together lead massive reversals of life standards and civil commons evolution across the globe. When $70 \%$ of France supports the strikes against raising the public pension age in the autumn of 2010, resistance to the totalizing private-profit agenda stands for civil commons only at the margins of its historic gains with its common life benefit still obscure. In the wider world, private money-sequence invades public 
sectors in every domain, the last great frontier of the world capitalist system. Civil commons are dismantled, defunded and restructured to serve the private-profit order and invariably bring in their wake decline in life goods and cost-efficiency for society - the unspeakable fact for even public broadcasters. On the global plane, the great disorder of private money-value growth cumulatively despoils humanity's universal life goods from the atmosphere and breathing air to the phytoplankton and fish stocks of the world's oceans.

\section{The Divided State: The Common Life Interest versus the Corporate Servo-Mechanism}

Life-value analysis recognizes that there is not one modern state, but two warring states within one: the now dominant state to grow private corporations and commodity markets at whatever cost to life capacities and their support systems versus public government to serve the common life interest of universal life goods for human life capacities for more people at more levels. In the defining lines of this still preconscious world war, the backwards or forward transformation of human society is decided. Without recognition of its life-and-death stakes and inner logic, there is no hope beyond political rhetoric. For on the make-or-break level of public funding and taxation, government functions and expenditures are increasingly structured to subsidize private-profit interests towards bankrupting public government itself, and thus also the possibility of social justice. We are already at this pass now. Longitudinal diagnosis reveals a system-wide pattern of subsidization of major forprofit corporations in staggering haemorrhages of public wealth into the global corporate maw: unceasing major tax cuts and write-offs to fractions of former liabilities to pay less tax than their lower-end employees; growing subsidies for extraction of public resources and pollutive commodity production; rising public subsidies for private automobile, weapons, aeronautical and commodity research and manufacture; perpetual expansion of heavy-gauge highways and police-and-prison systems tailored to private corporate interests; rising armed forces and corporate weapons production to guard these and other for-profit corporate appropriations and interests beyond home borders; ever increasing bankrolling of corporate-trade offices, negotiations and enforcements to systemize and extend corporate rights further within and across borders; and continued abdication of constitutional credit and currency creation to private banks for profit. All are justified as "necessary" and "in the public interest" until we recognize the opposite structure of facts, such as the unprecedentedly clear connection between the direct transfer of trillions of dollars of public wealth to failed private money-sequencers and banks who produce nothing and the public-sector and debt crises across the world since to pay the bills which bleed them dry. Life-blind categories of judgement and decision prop every step of society's reversal of a century of advances. The European Union whose public sectors and civil commons infrastructures have led the world are variously hollowed out to sustain the carcinogenic system. At the same time, public constitutional control of credit and currency remains blocked out and is nowhere in this era yet directed to funding of the common life interest and social justice-not to protect 
social and natural life support systems, not to secure employment for life-serving purpose.

In these ways beneath the surface play of phenomena, the corporate-person rights' system for private money gain coerces the world into civil as well as ecological breakdown. Yet the deepest civil commons remains unrecognized, the publicly instituted and protected exchange medium itself which has been wrested away by private forces - what Benjamin Franklin reported as the main reason the Thirteen Colonies rebelled against British rule, the outlawing of the "colonial scrip" by the 1775 Currency Act which had enabled the independent prosperity of the Colonies and whose seizure by the private Bank of England caused major depression. This is the private money-sequence appropriation of public currency and credit issue continuing today as the social gene of public dispossession across the globe. As long as its public and constitutional jurisdiction is not re-grounded in public control for life-serving purpose, the step by step breakdown of the life security of peoples and their life conditions passes undetected even by Marxian analysis. ${ }^{14}$

\section{The Life-Value Ecology of Justice: Bridging Rights and Obligations to the Civil Commons}

In Nature, rights and obligations do not exist. The right is to the stronger, and no obligations confine what is seized and predated. Yet what is not seen by those affirming the "right of the stronger" across species is that few or no beings survive in Nature whose functions do not contribute to their wider life-host. Scientific ecology has made this clear over the last 50 years, but it is a theme of understanding that goes back to the Tao-te Ching over 2500 years ago. Herein lies the natural basis for understanding human rights and obligations - a life-grounded ecology of justice at the human level. To put the matter boldly, the same logic of the italicized law can be applied to the human level in rights terms. Humanity evolves beyond the peckingorder, leave-to-die and predation system of Nature when its rules of reproduction regulate by life-protective rights and obligations. Even in Nature, the young are protected, fed and taught around the clock by the lives of their mothers in mammalian and bird species. . In classical and neo-classical market philosophy, however, not even this pre-human obligation exists. As Adam Smith says in a littleknown overview of the market's supply-demand system, "among the inferior ranks of people the scantiness of subsistence can set limits to the further multiplication of the human species; and it can so in no other way than by destroying a great part of the children which their fruitful marriages produce. (Smith, 1966, p. 85).

Notwithstanding the homicidal logic of the ruling market system and doctrine, the human right-obligation order supersedes the natural system and, as in all social order, is constructed by the rules or norms societies live by. For life-value understanding, rights for individuals depend on obligations fulfilled to the life-hosts that sustain them at social and natural levels. Just as social rules replace absolute rights of market property and trade structured to such mass human life sacrifice. The rightsobligations structure of society is life-blind until it is ordered to enable the lives of all its members by the greatest possible provision of universal life goods each requires to flourish as human. This is the life-value ecology of rights by which civil commons development has long been governed beneath principled attention and 
understanding-precisely what the globalizing private money-value disorder predatorily attacks. Wherever this system is not subordinated to civil authority as an instrumental mechanism of life goods provision (e.g., as efficient machine manufacturing and price mechanism within life-coherent constraints), it reverts to this predatory rule. Without social recognition and regulation of this predatory logic, this system can - and typically does - blindly destroy and despoil human and natural life support systems to maximize private money returns as an end-in-itself. When in opposition to this life-blind growth, the Council of Canadians or the Right to Food movement of India or other non-governmental civil commons formation stand instead for universal provision of these life goods on the basis of a National Health Act and Public Distribution System - the latter struggling against private-take norms at all levels to achieve a universal public distribution of food as a life-saver for half of India's children suffering from malnutrition-we observe the civil commons in action in both governmental and active-citizen forms. If we revisit the universal life goods defined in this study, we will be able to further find long-term movements of this kind operating beneath theoretical connection, a meta pattern of history not yet conscious of its meaning.

When even the world's richest men like Bill Gates and Warren Buffett try to organize their number to give away most of their wealth to social causes where human life is clearly at risk and in need of intervention-for example, malaria in the majority world where there is little market demand to generate private investment for maximal profit - we can rightly be concerned about their tax write-offs and privatefoundation powers as well as the token nature of this enterprise affecting a tiny segment of the deadly global injustice in isolated spheres. Life-value analysis at the system level recognizes that only civil commons formations backed by public funding and universal life-need programs can work at a social level and in the long term. Yet it also recognizes an important shift occurring - that those best at the private money-sequence game realize that something is wrong and must be responded to, the human vocation expressed even by them. Beneath such positive symptoms of which George Soros is perhaps the lead example, life-value understanding recognizes the deep-structural issue - that society's regulation to secure and provide life goods otherwise in short supply or its system failure to do so is what ultimately matters. The rules by which people live decide whether a society is well or ill, and whether it rises or falls in the long run. They form the moving line between healthy societies and diseased ones, between the well-being and the illbeing of human societies and communities across time and cultures. Life-and-death implications are thus built into governing rule systems which determine whether people are repressed and deprived or enabled to live and develop. Herein lies the lifeand-death choice-space of society. The deciding line is towards ever more socialecological disaster by the money-sequence disorder and its supreme right of private profit with no accountability to life requirements, or towards a life-valuing order of provision of universal life necessities for ever more and accountability to social and ecological life support systems. The former is society's cancer gene, and the latter its immune system and evolving humanity.

It is not as if we do not know this inner life-value logic in our own lives. Yet while global corporations are lavishly subsidized and armed-force defended by captive states they pollute the world at every level, draw down its non-renewable resources, 
competitively disemploy and underpay workers across cultures, systematically shirk public tax obligations and run down public infrastructures, destroy the habitat of species, and so on-all within the global market competition to survive as private money sequences, the master code of value absurdly presupposed as a law of nature. This is not what any sane individual would do in her own person, of course. Not even corporations will acknowledge this $i$ s what they do, but insist on the opposite in every ad. The human vocation comes out one way or another. Yet as we have seen, corporate-person law and rights dictate private money-sequencing as their sole obligation, and their meta program over the last 30 years has been an all out counterrevolution against the civil commons developed since 1929 in the face of the world capitalist Depression and the Nazi holocaust. "Economic efficiency and growth" always justify the system, but the reality is that this system wastes many times more life goods than all previous systems put together. It is, in fact the greatest diseconomy in history, but life-value diagnosis is required to see it. Whether a rules system produces life goods and conditions with non-waste as its ecology of value, or depredates them for private profit as its supreme law, is the true distinction between sustainable and unsustainable systems. Yet only judgment by life standards can distinguish between them. Thus, goods mean in truth life goods, not any priced commodity which may be bad for ecological and human life. Necessity means what is needed by the lives of human persons, not the demand of what those with money want to buy from private corporations. Supply is not excluded to priced commodities for profit, but provision of human life goods by all means-civil commons, ecosystem services and womens' unpaid work included. Productivity is not measured by ever more manufacture, transport and sale of profitable commodities by loot-andpollute methods at lower money costs, but productive gains in life goods produced and secured for citizens and peoples. The human vocation of life-value understanding and advance recognizes all this as self-evident. It is what conscious and life-conscious human beings already do in their personal lives as the inner logic of the life value code and is the basis for real "family values." At the macro level, it is what the civil commons infrastructures of societies evolve through generational time, including by a private market sector accountable to life standards. Ultimately all legitimate rights are linked to the provision of these life goods (true economic demand); while the only legitimate basis of work obligation is to contribute the hours required to enable this provision (true economic supply). This is the human vocation at the level of socioeconomic organization, and subsumes whatever serves lifecoherent human and ecological life capacity. It is not a blind a-priorism of socialism versus capitalism

Critical economic and social-justice theory begins to comprehend this logic of real economy and life-value right and obligation, but do not yet have the life-good criteria to ground soundly underneath the measure of money-value or political-party right which have, in fact, led to steeply shorter rather than greater supply of human life goods for the world, and more life-capital loss than ever before. On the ecological plane of species survival by species contribution to the natural life host, on the social justice plane of right-obligation due to provide for a human life for each, and on the economic plane of productive efficiency and non-waste, the ruling system has cumulatively and now fatally failed. The problem is that pervasive misrepresentation and partial views have blocked recognition of the disorder and the logic of its resolution. 


\section{From the Depression, Anti-Fascist War and Decolonization to the Corporate Occupation}

The war between life requirements of human beings and private money-rights for corporate persons has been an under-theorized contradiction. Before 1945 ended the most systematically genocidal system in history, the Nazis' proclaimed natural right to rule other societies by eradication of non-Aryan peoples followed upon earlier cultural genocides and enslavements of other peoples from Latin America to Africa to India and East Asia by a broader and longer-lived Euro-American colonialism. Accompanying and preceding these imperial systems there were the ecogenocides of the first peoples across the American hemisphere, while before and coincident with these there was the clearance of the village commons of the British countrysides during and through the rise of its world-wide empire. Analysis can track this ruling pattern of ecogenocidal rule back through millennia and before corporate rule to the command of Yahweh to "exterminate all the men, women and children" of the "Promised Land."

This enduring pattern of massacre, occupation, and exploitation where all rights favour one side only underlines the importance of Europe's emergence out of a continental zone of wars into an enduring multinational union of many-sided civil commons and rights of human life led world civilization. Yet the only lasting largescale social system in modern history to regulate towards social justice and universal human life goods provision for all citizens is being systematically traduced and reversed. Transnational corporate relocation of production to regions with no labour or environmental standards to sell back into societies to bankrupt their advanced and independent civil commons has been the unseen formula. Captive states extending cumulative public subsidies of every kind to these same borderless corporations has been the complementing formula for financial transfer to the rich. To celebrate the results has been the function of media disinformation. "The tough new global marketplace" is the master idea, as in John D. Rockefeller's early declaration: "The disparity in income between the rich and the poor is merely the survival of the fittest - the working out of a law of nature and a law of God" (McMurtry, 2010b). At the level of international law which has long moved beyond old-testament market theology, sustainment of the illegitimate order has required that no life-protective or life-enabling law is enforced. Instead unilateral private corporate rights are imposed by transnational trade treaties - the macro restructuring of the global system including now Russia and China. Overall this corporate war of movement explains why even in the aftermath of the self-caused corporate-bank collapse of 2008, virtually all public funds have gone to large corporate bank bailouts while the people impoverished by it - the disemployed, the home-expropriated, the pension-ruinedhave received nothing, and the civil commons been stripped to refund the parasitic rich. It follows from the still ruling agenda that human persons and nature itself progressively dissolve into functions or detritus of transnational corporate rule by private money-sequencing. Backed by countless rules enforceable against governments, corporate money-sequences rights reign. Except in pretence, real persons' lives and life support systems at individual or social levels do not factor in.

While corporate rule for private profit is assumed inevitable by "economic laws" and "human nature," it is in fact imposed by constructed corporate rights - the secret 
history of humanity since the before the Reagan presidency's turn from "human rights" to the "fight against communism" (essentially indigenous poor people fighting for land and a human existence). World War II, in contrast, was against rather than for fascism. History is decided, not fated. This war required civil commons to fight it - from public rations of scarce life goods to full employment of citizens. Over 30 years of civil commons building was then achieved while world rule for private money profit was contained and turned back by the global social turn. Its social formations evolved in mixed and socialist economies, and were backed by statesmen as well as workers and middle classes. Return of this civil-commons evolution occurs again in diverse ways in Latin America at the head of a growing repudiation of the "neoliberal model" in which the earth and society are reduced to transient instruments for private money sequencing to more.

Universal human life goods for all is the inner logic of purpose and development of this historic movement across generations and cultures. A 1944 State of the Union Address by U.S. President Franklin D. Roosevelt reveals the structural shift of official policy goals towards government by life values and standards against enemy powers within and without. Roosevelt said in précis: "We cannot be content if some fraction of people is ill-fed, ill-clothed, ill-housed, and insecure. True individual freedom cannot exist without life security. Regardless of station, race, or creed, there is a right to a useful and remunerative job, to adequate food and clothing and recreation, to a decent living, to freedom from unfair competition and domination by monopolies at home and abroad, to a decent home, to adequate medical care and the opportunity to achieve and enjoy good health, to adequate protection from the fears of old age, sickness, accident, and unemployment, to a good education."

Observe how comprehensive and concrete the universal life goods named here are. The human vocation, standards of life value, the life coherence principle, and civil commons constructs are all implicit. Yet Roosevelt was aware of the private corporate reaction still in force which had collaborated with the Nazis in armouredvehicle manufacture, information technology for concentration camps, and chemical and pharmaceutical production. ${ }^{15}$ From the ultimate socio-political conflict he was standing within, the "leader of the Free World" concluded: "Our rightful place in the world depends on how fully human rights have been carried into practice for citizens. For unless there is security here at home there cannot be lasting peace in the world. But there are grave dangers of rightist reaction and should it develop it is certain that, even although we shall have conquered our enemies abroad, we shall have yielded to the spirit of fascism at home."16 And indeed Roosevelt's civil commons project of universal human life rights has since been attacked at every stitch of historical construction by private money-sequence powers. He rightly foresaw that universal life goods accessible to all must be "carried into practice," or the "rightist redaction at home" and "the spirit of fascism" will prevail. One might conclude from post-1980 imposition of transnational corporate-right rule that the enemy Roosevelt alluded to has in fact won in both the US and the world, but in a different way than in the past. It has reversed the evolved social state by three deciding levels of "rightist reaction" which form a new strategic pattern into the present. My research over 25 years has found and confirmed a systematic structure underlying what we might call The Great Reversal. It can be concisely formulated at a high order level of conception as follows: (1) systematic defunding, privatization and reversal of evolving social sectors in the name of eliminating public debt and 
deficits caused in fact by i. compounding high-interest bank rates, ii. radical tax cuts to corporations and higher incomes, and iii. increased military spending; (2) by corporate-trade treaties with overriding rights decided and instituted outside elected legislatures and without electoral support by transnational corporate agents in and out of public office; (3) by private funding of propaganda against the social entitlements and for market-capitalist values, while increasingly tying higher research funding itself to corporate commodity and weapons development. ${ }^{17}$

The elements of this systematic pattern of "rightist reaction" to the present may be tested on all the phenomena of cutback on civil commons formations over the last 30 years, and will find few deviations from it. The evidence has, in fact, become ever more abundant. These regulating principles continue today beneath public and scientific reports, and all deprive most people of the life goods they would otherwise have access to had civil commons development continued its trajectory of advance from the war against fascism. Claims or assumptions that social programs became "unaffordable" for government are silly because they ignore the general facts that the debt and deficit growths used as pretext for social-program slashing were over $94 \%$ due to prior tax cuts to corporations and the rich (Canada's typical pattern), and to $20 \%$ prime compound-interest rates charged to governments by private banks silently appropriating the constitutional right of governments to issue credit through public treasury (as swiftly occurred for Wall Street later). The "unaffordable" argument also ignores the general fact that government tax and other subsidies to private arms manufacturers and agribusiness alone exceed the cost of social programs in the US One needn't refer to Big Lies to recognize them and their underlying pattern of serving one factional interest-private-profit money sequencing. Since the fall of the Soviet Union in 1991, there has been no need to compete with better social programs and universal life goods because now transnational corporate persons have the right to do as they please where there are no obstacles like free unions or independent democratic procedures. Globalization in this condition is what is never reported in legislatures or by the media-the globalization of corporate-person rights as absolute, unaccountable, and unlimited - in short, fascism in a new form. ${ }^{18}$

Since the law of motion of this globalization is to become more private money demand without boundary across all borders and domains, its rule technologically expands by increasingly powerful instruments from earth-moving machinery and ocean-bottom drillers to genetically modified organisms and financial derivatives within government-deregulated-and-subsidized conditions. Weapons of mass destruction and monopoly mass media are then the transnational guarantors of world submission. Social or environmental justice in this reigning disorder does not factor in except as false ideology, and is attacked where it does-unless, as in Brazil, the economy functions far more efficiently with guaranteed incomes for poor mothers, or China, where private banks are on a tight leash, or Venezuela or Bolivia where public oil wealth is allocated to public purposes. The war goes on one way or another, blinkered out in the Anglo-American world and its client dictatorships. It always goes better for life and justice when the disorder is recognized and put under publicly accountable control, and always worse if not. Where the transnational corporaterights reign is not put on a leash or public resources reclaimed, the worst creeps rapidly and pervasively. At the macro level, human beings are ever more widely structured as inputs to serve the corporate money-sequence value mechanism while 
public-sector, farming and home-worker positions are eliminated continuously in tens of millions. On the environmental level, there is no research in the last 30 years that rebuts the general fact that every life-system on the planet is in decline or collapse. While invariably represented by economists and corporate media as "competing for prosperity and freedom," life-value understanding recognizes the opposite in fact-an absolutist social construction led by armed force and command treaty at every step that deprives ever more people of their necessities of life and, thus, their freedom.

While rights in general mean lawful or law-backed claims to goods of any kind, the regulating rights of the global corporate system are in fact absolutist rather than democratic because they: (1) recognize only the trans-border rights of money-capital owners or "investors"; (2) exclude all rights not backed by private money demand, and (3) legally erase any national legislation not in compliance with these treatyinstituted rights. The trade-and-investment treaties defining this rights system are anchored in the North American Free Trade Agreement (NAFTA) and the subsequent World Trade Organization (WTO) which require that foreign corporations receive equal treatment "without discrimination" in all societies so contracted in all matters of purchase, sale and subsidy, as well as the corporate-person or "investor" right to sue governments which do not comply or which are alleged to have caused "loss of profit opportunity" (e.g., by banning advertisements for a commodity such as cigarettes or regulating against a fuel additive with neurotoxins for national health reasons). At the same time, what used to be a matter of political debate and judgement within national borders-for example, to exchange domestic market access and natural resources for reciprocal returns from the corporations receiving these rights (e.g., manufacturing in the host country for free access to the domestic auto market) - have been outlawed. With all other deviations by democratic selfgovernment, they are punishable by severe financial or trade penalty. The ultimate right to exchange between domestic public and foreign corporation is thereby abolished in favour of unilateral corporate rights - the only actual content of tradeinvestment treaties in this period.

Much follows from absolutist prescription against the sovereign rights of government to negotiate with foreign corporate persons - in fact, the abolition of their free trade. Transnational corporations receive what they have not had since decolonization -the rights to sell in foreign markets without impediment, to buy domestic industries without limit, to receive guaranteed free access to the natural resources of other societies, and to receive government subsidies on a citizen basis. Sovereign government over society's mode of reproduction is in this way replaced by foreign corporate rights as "non-discrimination" against them. No rights, on the other hand, are granted to workers, or citizens. In this new "free trade" arrangement, no government at any level may pass legislation which infringes these corporate rights or "profit opportunities," with central trade-lawyer tribunals judging in secret and punishing governments for deviation from the new rules. "Performance requirement" and "process of production" condition by host or importing society, formerly givens of democratic self-government, are made illegal and subject to unsustainable financial punishment. The ecological consequences are least of all discussed. Unconditional rights of transnational corporations to nationally owned natural resources for exploitation of oil, minerals, fish and timber permit their worldwide corporate looting of one region after another with no accountability under the 
rules for future supplies or ruinous effects (U.S. exceptionalism aside). With the binding regulations of these corporate rights upheld and adjudicated by secret meetings of trade tribunals, proceedings are unpublished and judgements to enforce the "least trade restrictive practices" in all matters are final and not appealable. The new rules by which societies' economies must live are, however, effectively outside public debate, as may be tested by seeking where they are identified anywhere in public policy forums and economic policy discussions. Yet this inner logic of supreme rights to corporate persons and none to living persons has received little academic attention, including by moral philosophy, justice theory and ethicist literatures. Because the new regulatory apparatus runs to over 20,000 pages of legal jargon in the prototype NAFTA, few have the skill or patience to read the defining terms. Because as well the myriad articles nowhere reveal the underlying principles regulating them, the philosophical under-labour required to decode their moral meaning has been missing. The ruling corporate rights structure has also been obscured by confusing it with the opposite ordering of the local free market which occurs on public property, sells local produce and crafts, does not advertize, prepackage or expatriate profits, has no external hierarchy or stock-profit demands, does not lobby governments for handouts and favours to dominant sellers, and cannot manipulate supply or demand. The global corporate "free market" is, in short, the opposite of its representation. As elsewhere, the meanings of words are reversed. In line with the unobserved sea-shift across borders in the name of opposite meanings, rights of human beings and fellow life do not count in. Indeed individual rights become the rights of corporate persons instead - rights to commercial free speech with no criterion of factual truth, for example, and to anonymous external funding of election propaganda with no limit as, again, "freedom of speech." The equal rights of the U.S. Fifth Amendment intended to protect freed slaves are also appropriated by corporations as "equal persons" so that $99 \%$ of litigation for these equal rights are to protect these "corporate persons" which have been fabricated by law. Life-protective and enabling rights of real persons are at the same time expelled from human work across domains.

Corporate rights have become so unquestioned that Jürgen Habermas adopts their rule as a technical given -"the technical-administrative apparatus" of the "norm-free sociality" of the economy. The most powerful norm system ever is thus assumed as the opposite at the highest levels of theoretical research publication. Life-value analysis, in contrast, recognizes the absurd misrepresentation of reigning norms as not norms. No social system is decided by natural laws. As social constructions, rule systems vary widely from social order to social order through cultures and the means available. In our era, society's rule and rights systems have developed in fact a primary contradiction between them: human-life-protective/enabling norms and rights versus money-capital-protective/enabling norms and rights. The latter, however, rule and do so by being ludicrously conceived as not norms at all, but technical givens like the law of gas expansion driving wheels. The underlying normative contradiction is even deeper than between classes or cultures: It is between human and ecological life's inherent requirements both to reproduce and biodiversify in more forms and unliving money-capital's imperative to produce private commodities and profit in violation of life needs and capacities at every level. The former increasingly necessitate life standards to enable human life and life 
conditions to survive and flourish (the civil commons), while the latter expands whatever cumulative degradation and exhaustion of resources and sinks it causes (which results from corporate rights without accountability).

Individuals as well as states have become creatures of this ruling meta program. For grounding in a concrete particular case, consider a microcosm of the corporate rights system, a phenomenological decoding of the rights and freedom of the individual in this ruling disorder. While individual right and freedom appear to be another indisputable fact repeated mantra-like across the fields of public and private meaning, life-value analysis decodes a more sinister pattern of individual unfreedom and life oppression. Thus, for example, the "free individual expressing his rights" becomes his spending on and consuming power-motor commodities. Decoded s/he is propelled along the following steps of self right: "(1) I the consumer has a right to (2) the hearing and sight fields around me (2) because of my high-cost commodity motor to (3) occupy the public life space I choose (4) with no barrier to this consumer enjoyment nor (5) rations for what grows scarcer for the world (6) whatever sentience of other life is violated because (7) I have bought and paid for it and (8) this is my right and my freedom. Life-value analysis looks beyond such incantations of individual rights and freedoms to what is, in fact, a life-blind expression of the corporate meta program in individual form with no obligation to recognize the requirements of other life.

\section{Re-Grounding In and Advancing the Human Rights Which Have Been Won}

There has in fact been a long war of corporate rights against life security of human communities and ecologies over centuries-from the private East India Company over 250 years ago ruling entire peoples with supreme rights over life and death to more omnipresent global corporations today competitively indifferent to any lifedestructive cost so long as it is profitable to be so. While heinous life consequences are ignored, projected onto opponents and left to deepen and spread so that all may seem hopelessly bound to disaster, life-value analysis recognizes a deeper and more human substructure long developing beneath the corporate despotism. It recognizes for principal example the universal life-protective norms that have been recognized since the 1939-45 World War which are of life-and-death necessity and advanced in meaning. The problem is not that such civil norms have not been recognized across national and cultural borders. It is that they have been usurped by global corporate rule and backed by captive states to be above the law. Consider the United Nations Universal Declaration of Human Rights instituted within four years of Roosevelt's "New Bill of Rights" near the end of the World War. One underlying principle governs each and all of the rights it recognizes - to protect and enable human life in all domains. Each is also directed against a common enemy - the forces known to violate these human life rights. The U.N. Declaration is worth citing in full to recognize their underlying life-value logic: the rights to "freedom of speech and belief," "freedom from want," "dignity and worth of the human person," "not to be subjected to - inhuman or degrading treatment and punishment," "equal access to public service," "universal and equal suffrage," "social security-and [the resources required for] the free development of personality," "work [and]-just and favourable conditions of work," "rest and leisure," "standard of living adequate for the health 
and well-being of himself and his [sic] family, including food, clothing housing and medical care," and "education - and equally accessible higher education." The underpinning principle of all of these rights, the one onto-ethical ground of which each is another and complementary aspect of an implied moral whole, is to enable human life against its many-sided oppression. The U.N. Declaration of Human Rights can thus be understood-although this meaning has eluded philosophy, law and economics - to be a universal statement of life-value morality and social justice agreed to by states across cultures. Revealingly the Universal Declaration of Human Rights has been criticized from both the left and the right. The Marxist conceives it as a "merely ideological mask" of capitalist reality, while the Right denounces it as "dangerous nonsense" and "communism in disguise." Yet the real problem is that the common life support systems required for these human life rights are the still missing ground - the infrastructures not yet made conscious as the defining substance of human advance.

States jealous of their sovereignty have not prevented universal life rights so much as imperial corporate states have prevented popular governments from the social reforms necessary to realize them. For example, there has been a United Nations' Charter of Economic Rights and Duties of States since 1974 which spells out the conditions required for human life standards to be economically instituted at a state level. This codified global agreement was passed by the United Nations General Assembly by a 120-6 vote just after the U.S.-supported and murderous military coup of the democratically elected government of Chile. While this U.N. Charter of Economic Rights was cooperatively written and near-unanimously supported by nation-state representatives to the U.N. from across the world to lead another kind of globalization than the one unveiled by the U.S.-managed Pinochet coup in Chile, it was effectively annulled by extra-parliamentary passage of the transnational corporate rights edicts explained above. Under this new world order, the terms of the Charter of Economic Rights and Duties of States were silently overridden in their entirety - in particular the "sovereign and inalienable right of every state to choose its economic system," and its "permanent sovereignty, including possession, use and disposal over all its wealth, natural resources and economic activities." The political rights of states "to regulate and exercise authority over foreign investment within its national jurisdiction" and "to regulate and supervise the activities of transnational corporations" were erased by the new global corporate-rights system. Ensuring that this reversal was as inconspicuous as possible, the new transnational corporate-rights system was undiscussed in legislatures, unread by legislators, and formed, adjudicated and enforced outside of electoral processes and democratic accountability. David Rockefeller, a leader of "the new world order" and founder of the transnational Bilderberg meetings behind it, frankly described its meaning to the 1991 gathering of world leaders in a leaked transcription: "A supranational sovereignty of an intellectual elite and world bankers is surely preferable to the national autodetermination practised in past centuries."

Private corporate rights were thus given the force of supreme world law without recognition of the fact that the "plan for world rule" had long been ascribed to the much weaker Soviet Union. Just as the life-protective rights of the 1948 U.N. Declaration were earlier decoupled from the economic conditions required for their realization, and just as the collective rights of national economies to develop in 
control of their own natural resources and markets under the protection of the U.N. Charter of Economic Rights were overridden, so also further life-protective rights formed by the United Nations were ignored or vilified. Examples include, but are not confined to, the U.N. Convention on the Prevention and Punishment of the Crime of Genocide (1951), United Nations Convention on the Political Rights of Women (1952), and the Convention on the Rights of the Child (1986). Binding international criminal law existing in some form since the Nazi war leaders were tried under the Nuremburg Charter to protect the lives of people against the "supreme crime" of a war of aggression and "all the crimes following from it"- "war crimes," the "crime of genocide" and "crimes against humanity" - has also stayed unenforced since. Its final institutional formation as the International Criminal Court (I.C.C.) in 2002 has been restricted to prosecution of unallied third-world leaders, or-in Guantanamo style-young Muslims resisting U.S.-led NATO occupation of Afghanistan charged with "war crimes." The "supreme crime of a war of aggression" by the major states has at the same time been kept beyond the Court's jurisdiction. As in the 2003 invasion of Iraq and corporate privatization of its economy and oil extraction, the global corporate rights system proceeds across borders and above the law as did the prior fascism. But it does so more long-lastingly by a money-led occupation of electoral processes and government ministries, and the extra-Parliamentary dictates of transnational treaties.

Today we may observe life-enabling and protective rights receiving little or no enforcement, while private money-capital rights of corporations backed by transnational U.S.-led armed force are systematically prescribed in trade treaties to violate them. With widespread confusion and cynicism about "human rights," and corporate-person rights overriding them under the mask of "free trade," one might think the corporate war against life-value social justice had been won. Yet lifeprotective norms still continue to evolve beneath the interregnum. One need only look at the unprecedented world charters and covenants cited above to see a 70 -yearlong swing towards international life-security norms before unimagined. The problem is in implementation. Legal scholars widely agree that the issue with even the legally binding covenants on life-protective rights is the problem of enforceability across borders. Few or none see that if the same regulatory instruments were applied as they are in the enforcement of private corporate rights across borders, the problem of enforceability would be solved. Such enforcement of universal life-protective rights, however, is so effectively blocked that not even learned advocates of human rights recognize the possibility. All that is required is the inclusion in international trade treaties of those life standards which are already formed and agreed upon across nations. The United Nations International Covenant on Economic, Social and Cultural Rights (1966), for mainspring example, is both legally binding and global in jurisdiction. It is an established global legal and lifevalue ground from which to enforce life-protective rights against unaccountable global corporate money-rights. Yet its existence and its articles are not recognized by over $99 \%$ of the population in a world whose public media and journals are overwhelmingly owned by a few private transnational corporations. The terms of the International Covenant are nonetheless of great significance because they are legally binding and their unifying meaning is to guarantee universal access to universal human life goods: namely, "just and favorable conditions of work," "a decent living for themselves and their families," "safe and healthy working conditions" (Article 7); 
"the right of everyone to form trade unions - to social security including social insurance" (Article 8); "the right of everyone to an adequate standard of living," to "an equitable - environmental and industrial hygiene" (Article 11), and to "distribution of world food supplies in relation to need"(Article 12), and "primary education compulsory and free to all" as well as "equally accessible" and "progressively free" provision of "higher education" (Article 13). We may see how these articles of the binding International Covenant are all subsumed by the Universal Human Life Needs and Goods of Humanity spelled out in an earlier subsection. In deeper implicit significance, they express the underlying life-value onto-axiology, life-coherence principle, and civil commons meaning as so far recognized in international law.

It is as if the principled grounds and theory of life-value understanding were at work as the higher value syntax of human and civil commons evolution underneath the private corporate occupation and ecogenocidal exploitation of life support systems. What has been overlooked in the human rights struggle, however, is the linkage of rights to obligations at the economic level-not only to fellow human but to ecological requirements themselves. This is what the human vocation and civil commons movement bridge towards in the next steps of humanity's social evolution. How to live - critical philosophy's oldest question - is not only an individual issue, but more primarily a social one. A life-coherent rule system has already been largely achieved in international law and the most developed communities. We already know it is possible to agree upon the terms across diverse cultures because they have already been defined and signed as a solemn covenant across diverse nations. All of the life standards named in the International Covenant are, in fact, governed by the same underlying principle governing advanced societies-provision of that without which human life capacity is always reduced. Together these life goods and standards carry the full substance of what the world's nations have agreed that all humanity requires to survive and flourish, however different its cultures. Yet the private money-sequencing system and corporate-right rule have warred upon these universal life standards at all levels. Thus not one article of this International Covenant on Economic, Social and Cultural Rights has been permitted into the solely effective mode of transnational law that humanity knows - its economic treaties. Even when operationalization of life-protective law in this treaty system is known to work-as the 1989 Montreal Ozone Protocol has proved by its explicit inclusion in the NAFTA prototype of the WTO and general adhesion to it - the ruling meta-program blocks even public conception of the principle. It is forgotten as an exception once the emergency has passed. In more evolved form, the European Union has long made corporate rights accountable to human life rights across borders by its Community Charter of Fundamental Social Rights. Its underlying principle of governance is principally livelihood rights: to equitable remuneration; a maximum number of hours per working week; free association in trade unions and collective bargaining; professional training; sex equality; minimum health and security provision; employer-employee consultation and participation; a minimum working age of 16; minimum pension rights; protection for disabled workers; and prohibition of slavery, forced labour and the use of the human body or body parts for financial gain.

Predictably, no level of the European Union's social organization has not been attacked by European big business and transnational media, as does the Economist in 
every issue. This is the predictable reaction of the global money faction whose sequences of control and growth run through elected heads of state and politicians themselves. Nonetheless the integrated moral-economic European model has already evolved over half a century regulated by life standards, and has worked far better than any other international paradigm over 60 years in protecting the lives and freedoms of citizens. Of course, it is everywhere denigrated by the corporate politicians and media for restrictions on "globally competitive" practices with no life standards, so that the life security and freedoms of the great majority are ridden under even as I write. This is the post-1945 neo-fascist war under cover, and the race to the bottom of life standards for the rest of the world. Yet it only succeeds so far as it remains uncontested as corporate-right usurpation of humanity's social evolution, and cumulative destruction of the life-carrying capacities of the planet itself. Recognition of the life-value logic of social justice and its civil commons foundation are the missing ground and link of human emancipation.

\section{Notes}

1 The fallacious logic and devious strategy of Locke's argument is anatomized step by step in Value Wars: The Global Market versus the Life Economy (London: Pluto Press) 65-73.

2 The formal axiom of life value is: $x$ is of value if and only if, and to the extent that, it constitutes or enables a more coherently inclusive range of life than without it: within the fields of life of thought (conceptual and image), felt side of being (sentience, emotion, mood), and/or action (animate movement through space-time). Conversely, $\mathrm{x}$ is of disvalue if and only if, and to the extent that, it disables life so defined.

3 Verified by author May 1, 2011.

4 Philip Mirowski's Machine Dreams (2000) is a very informed study tracking the machine model in contemporary market economic theory into the "automaton theater" of economic, military and decision-theory research today - extending the magic thinking of the invisible hand's necessitation of the best of possible worlds into the mechanism of a life-blind system automatism.

5 Bernard Hodgson spells out the implications of Edgeworth's principle in his Economics as Moral Science (Heidelberg: Springer Press, 2000).

6 Edward Bernays, a nephew of Freud, explains how in his Propaganda (1933) New York: Liveright. As the primary pioneer of modern mass-market conditioning, he identifies the key of the process is to appeal to and control unconscious desires to sell commodities and manufacture social consent at the same time. My essay entry, "The Ruling Group-Mind" (Encyclopedia of Case-Study Research, 2008) spells out the unexamined premises and lifedestructive consequences of this and other group-mind phenomena.

7 Although. G.A. Cohen favourably cites Richard Titmuss in his Rescuing Justice and Equality (2008) as advocating the individual motive force of, nicely put in the abstract, "principled commitment and fellow feeling" (p. 189), neither he nor Titmuss recognizes the objective civil commons principles which unify and define these life-support institutions across cultures and over millennia.

8 Amartya Sen's Nobel Speech on "Social Choice" preconsciously reveals the problem. In his immense bibliography, there is no concept of social choice he reports that does not assume it as an aggregate of individual agents choosing in market, electoral or other such atomic grid of choice space

9 Thus as in-all $\$ 12$ trillion-plus of government money was extended in private financial arrangements in the US to "get credit going again," not even this function was remotely 
served. Senator Bernie Sanders reports the secrecy surrounding these facts that he was only able to discover by an amendment to federal financial reform legislation, $<$ http//sanders.senate.gov> accessed 19/12/2010.

${ }^{10}$ Amschel Mayer Rothschild famously said in 1838, "Permit me to issue and control the money of a nation, and I care not who makes its laws." There is much fact to support his view. Even the world's most powerful man decades earlier, Napoleon, depended on privatebank credit for his wars of expansion until, growing tired of the negative effects on business and in light of Napoleon's claim that the Bank of France "belongs more to the Emperor than to the shareholders," the private-bank creators of credit shifted alliances through a regime change. Abraham Lincoln decades later noted the long-term adverse effect of the private "money powers" on America when he said shortly before his assassination: "The money powers prey on the nation in times of peace and conspire against it in times of adversity. The banking powers are more despotic than monarchy, more insolent than autocracy, more selfish than bureaucracy. . . . As a most undesirable consequence of the war, corporations have been enthroned, and an era of corruption in high places will follow. The money power will endeavour to so prolong its reign by working on the prejudices until the wealth is aggregated in the hands of the few, and the Republic is destroyed" (cited by Andrew Gavin Marshall in Chossudovsky and Marshall (Eds.), The Global Economic Depression (2010), pp. 310-11).

${ }^{11}$ Few realise that Pareto's classic is based on dyadic asset exchange with no relation to life needs, given distribution, work hours, ecological support systems, or economic performance.

12 The corporate-servant state and academies enable the equalizing pathology. In Britain's Department of Health under new "Big Society" Conservative government, for example, the alcohol "responsibility group" is chaired by the Wine and Spirit Trade Association, diet and health is dominated by processed and fast-food corporations, and the sub-group on calories is chaired by Pepsi-Walker Chips. (Felicity Lawrence, "Fast food firms get health role," Guardian Weekly, (19/11/2010). North American university researchers meanwhile lead "the life sciences" - a re-brand term coined by industrial food giants - in commercial research in genetic contamination and agricultural-consumer products with no life standards.

13 This argument is made in McMurtry, "The Case for Children's Liberation," Interchange (1979-80) 10(3), with Critical Response and Reply.

${ }^{14}$ McMurtry (1999/2002), The Cancer Stage of Capitalism (London and Tokyo: Pluto and Springer Press) explains this anomaly and the underlying money-sequence source and cause of cumulative world system collapse. Ellen Brown (2010), The Web of Debt (Baton Rouge, Louisiana: Third Millennium Press) provides a thorough historical account of the private money power's control and predation of public currency from before 1776 to the Wall Street public bailout since 2008 .

15 Little known even today is that the Ford, General Motors, IBM and Dupont corporations produced for the Nazi war machine in these functions even after the US was at war with it (Charles Higham, Trading with the Enemy: An Expose of the Nazi-American Money Plot 1933-1949. New York, Dell Publishing Co., 1983). Moreover these corporations received government compensation for their bombed factories and losses in Germany after the war was ended, an indication of the supreme and borderless power wielded upon which the "New World Order," a Nazi concept, was instituted by national and international mechanisms of law identified in this paper.

16 This was the preamble to Roosevelt's introduction of The Second Bill of Rights in his State of the Union Address, January 11, 1944 before his untimely death prevented its formalization as policy and law.

17 I have tracked these strategic patterns in depth in prior work such as Unequal Freedoms: The Global Market as an Ethical System (Toronto: Garamond/University of Toronto Press, 1998).

18 The underlying fascist logic is explained in my Fascism and Neo-Conservatism: Is There a Difference? (1984), Praxis International 4 (1), 86-102. 


\section{References}

Bernays, E. W. (1933). Propaganda. New York, NY: Liveright.

Chossudovsky, M., \& Marshall, A.G. (Eds.). (2010). The global economic crisis: The great depression of the XXI century. Montreal: Global Research Publishers.

Cohen, G. A. (2008). Rescuing justice and equality. Cambridge, MA: Harvard University Press.

Edgeworth, F. (1932). Mathematical psychics. London: London School of Economics.

Glasbeek, H. (2002). Wealth by stealth: Corporate crime, corporate law and the perversion of democracy. Toronto: Between the Lines Press

Higham, C. (1983). Trading with the enemy: An expose of the Nazi-American money plot 1933-1949. New York, NY: Dell Publishing Co.

Hodgson, B. (2001). Economics as moral science. Heidelberg: Springer Press.

Huxley, A. (1947). Point Counter Point. London: Chatto and Windrus.

International Forum on Globalization (1998). The Siena declaration on the crisis of economic globalization. Siena, Italy.

Locke, J. (1980). The second treatise on government. Indianapolis, IN: Hackett.

Marx, K. (1986). Capital, vol. 1. Moscow: Progress Publishers.

McMurtry, J. (1979-80). The case for children's liberation. Interchange, 10(3), 10-28

McMurtry, J. (1984). Fascism and neo-conservatism: Is there a difference? Praxis International, 4(1), 86102.

McMurtry, J. (1998). Unequal freedoms: The global market as an ethical system Toronto and Westport CT: Garamond and Kumarian.

McMurtry, J. (1999). The cancer stage of capitalism. London and Tokyo: Pluto and Springer Press.

McMurtry, J. (2002). Value wars: The global market versus the life economy. London: Pluto Press.

McMurtry, J. (2008). The ruling group-mind. In A.J. Mills, G. Durepos, \& E. Wiebe (Eds.), Encyclopedia of Case-Study Research (pp. 790-793). Toronto: Sage.

McMurtry, J. (2009). Rationality and scientific method: Paradigm shift in an age of collapse." Interchange, 40(11), 69-91.

McMurtry, J. (2010). What is good? What is bad? The value of all values across time, place and theories. Oxford: Eolss. Publishers.

McMurtry, J. (2010a). Reclaiming rationality and scientific method: The life coherence principle as global imperative. Retrieved from: http://www.globalresearch.ca/index.php?context=va\&aid=21302

McMurtry, J. (2010b). The disparity in income between the rich and the poor is merely the survival of the fittest: the working out of a law of nature and a law of God. Retrieved from www.policyalternatives.ca/publications/monitor/back-good-old-days.

Mirowski, P. (2000). Machine dreams. Cambridge: Cambridge University Press.

Nussbaum, M., \& Sen, A. (Eds.). (1993). The quality of life. Clarendon: Oxford University Press,

Nussbaum, M. (2000). Women and human development/The capabilities approach. New York: Cambridge University Press.

O’Neill, O. (1998). Towards justice and virtue. Oxford: Oxford University Press.

Pareto, V. (1971). Manual of political economy, New York: A.M. Kelley.

Polanyi, K. (1944/2000), The great transformation. Boston: Beacon Press.

Rawls, J. (1971). A theory of justice. Cambridge Mass: Harvard University Press.

Sen, A. (1992). Inequality reexamined. Cambridge Mass: Harvard University Press

Sen, A. (1998). The possibility of social choice. Trinity College, Cambridge: 1998 Nobel Lecture in Economics. Retrieved from http://nobelprize.org/nobel_prizes/economics/laureates/1998/senlecture.pdf

Smith, A. (1966). An inquiry into the nature and causes of the wealth of nations. New York: A.M. Kelley.

Titmuss, R.M. (1968). Commitment to welfare, London: Allen and Unwin.

Turner, T., \& Brownhill, L. (2001). Gender, feminism and the civil commons. Canadian Journal of Development Studies, XXII, 819-855.

Weisbrot, M., Baker, D., \& Rosnick, D. (2006). The scorecard on development: 25 Years of diminishing progress. International Journal of Health Services, 36, (2): 211-234.

Woodhouse, H. (2009). Selling out: Academic freedom and the corporate market. Montreal \& Kingston: McGill-Queen's University Press. 